\title{
Atmospheric and Climatic Drivers of Tide Gauge Sea Level Variability along the East and South Coast of South Africa
}

\author{
Bernardino J. Nhantumbo ${ }^{1,2,3, * \mathbb{C}}$, Björn C. Backeberg ${ }^{2,4,5}\left[\right.$, Jan Even Øie Nilsen ${ }^{5,6}\left(\mathbb{D}\right.$ and Chris J. C. Reason ${ }^{1}(\mathbb{D}$ \\ 1 Department of Oceanography, University of Cape Town, Rondebosch 7701, South Africa; \\ chris.reason@uct.ac.za \\ 2 Nansen-Tutu Centre for Marine Environmental Research, Department of Oceanography, University of Cape \\ Town, Rondebosch 7701, South Africa; Bjorn.Backeberg@deltares.nl \\ National Institute of Meteorology_INAM, Maputo 256, Mozambique \\ 4 Deltares, 2600 Delft, The Netherlands \\ 5 Nansen Environmental and Remote Sensing Center, 5007 Bergen, Norway; jan.even.oeie.nilsen@hi.no \\ 6 Institute of Marine Research, 5817 Bergen, Norway \\ * Correspondence: b.nhantumbo@gmail.com
}

Citation: Nhantumbo, B.J.;

Backeberg, B.C.; Nilsen, J.E.Ø.;

Reason, C.J.C. Atmospheric and

Climatic Drivers of Tide Gauge Sea Level Variability along the East and South Coast of South Africa. J. Mar.

Sci. Eng. 2021, 9, 924. https://

doi.org/10.3390/jmse9090924

Academic Editor: Rodger Tomlinson

Received: 20 July 2021

Accepted: 20 August 2021

Published: 26 August 2021

Publisher's Note: MDPI stays neutral with regard to jurisdictional claims in published maps and institutional affiliations.

Copyright: (c) 2021 by the authors. Licensee MDPI, Basel, Switzerland. This article is an open access article distributed under the terms and conditions of the Creative Commons Attribution (CC BY) license (https:// creativecommons.org/licenses/by/ $4.0 /)$.

\begin{abstract}
Atmospheric forcing and climate modes of variability on various timescales are important drivers of sea level variability. However, the influence of such drivers on sea level variability along the South African east and south coast has not yet been adequately investigated. Here, we determine the timescales of sea level variability and their relationships with various drivers. Empirical Mode Decomposition (EMD) was applied to seven tide gauge records and potential forcing data for this purpose. The oscillatory modes identified by the EMD were summed to obtain physically more meaningful timescales-specifically, the sub-annual (less than 18 months) and interannual (greater than two years) scales. On the sub-annual scale, sea level responds to regional zonal and meridional winds associated with mesoscale and synoptic weather disturbances. Ekman dynamics resulting from variability in sea level pressure and alongshore winds are important for the coastal sea level on this timescale. On interannual timescales, there were connections with ENSO, the Indian Ocean Dipole (IOD) and the Southern Annular Mode (SAM), although the results are not consistent across all the tide gauge stations and are not particularly strong. In general, El Niño and positive IOD events are coincident with high coastal sea levels and vice versa, whereas there appears to be an inverse relationship between SAM phase and sea level.
\end{abstract}

Keywords: tide gauge sea level variability; Southern Africa sea level variability; atmospheric and climatic drivers

\section{Introduction}

Tide gauge data around southern Africa have been used to investigate sea level variability on only a few occasions in recent years [1]. This is because of the absence of good-quality, long-term sea level records [1-4]. Studies are needed in spite of this limitation in some regions to avoid the use of the global ocean mean estimate rates as a reference for future projections on regional and local spatial scales (e.g., [1]).

Around southern Africa, various authors have already carried out investigations on timescales of sea level variability and their possible driving mechanisms, based mainly on tide gauge records, daily and monthly means. Daily based sea level records have shown variability that ranges from 3 to 7 days or longer at some sites, but not longer than one month (e. g., [5-9]). The variability is due to the passage of weather disturbances such as cold fronts, ridging anticyclones and mesoscale atmospheric coastal lows [10,11], which propagate west to east along the South African coast (e. g., [5-9]).

Using monthly means from the west coast of southern Africa, timescales of sea level variability ranging from months to years have been found (e.g., [2,7,12]). The timescales 
were grouped into three categories: (1) high-frequency (synoptic), (2) seasonal and (3) interannual contributions. The synoptic contributions were attributed to the effect of the coastal wind stress associated with mesoscale and synoptic weather systems. The seasonal contribution was associated with seasonally varying wind patterns. The interannual contribution was associated with the occurrence of the El Niño-Southern Oscillation (ENSO) phenomenon in the Pacific Ocean, via sea surface temperature (SST) modulation along the west coast of southern Africa. This SST modulation was found to start further north in the eastern equatorial Atlantic [2,13]. ENSO may also modulate the frequency and intensity of the various weather systems that directly affect sea level (e.g., [11,14]). The synoptic and seasonal contributions were suggested to be responsible for over $55 \%$ and $25 \%$ of the monthly sea level variability, respectively [2].

Han et al. $[15,16]$ provide some insight into how sea level has varied along the east coast of southern Africa, although their study aimed to describe the driving mechanisms of Indian Ocean sea level variability on interannual and decadal timescales. Using both monthly tide gauge and satellite altimetry sea level observations, [17] suggest that on timescales ranging from a few months to decades, sea level anomalies along the coast of South Africa are associated with absolute dynamic topography variations in the Agulhas Current core. Additionally, the authors suggest that these absolute dynamic topography variations in the Agulhas Current core are in response to displacements of the current both near and offshore from the coast during eddy and meander events.

Along the east and south coast of South Africa, the studies cited above suggest that detailed information on the driving mechanisms of the timescales of daily means of tide gauge records can be found. However, monthly means of tide gauge records have been poorly explored in studies of atmospheric and/or climatic drivers of the timescales of sea level variability along the east and south coast of South Africa (Figure 1). Therefore, there is a need to improve our understanding of local and regional sea level variability, taking advantage of the extended monthly sea level data used in previous studies, most of them dated in the 1980s. The objective of this study is to determine the timescales of sea level variability and identify corresponding drivers. Empirical Mode Decomposition method (EMD) $[18,19]$ was applied to assess different modes (timescales) of sea level variability. Where possible, the separated EMD modes have been compared with previous results in the literature. This paper is structured as follows: the data and methodologies applied in this study are described in Section 2, the results and discussion are presented in Sections 3 and 4 respectively, and the summary and conclusions are given in Section 5.

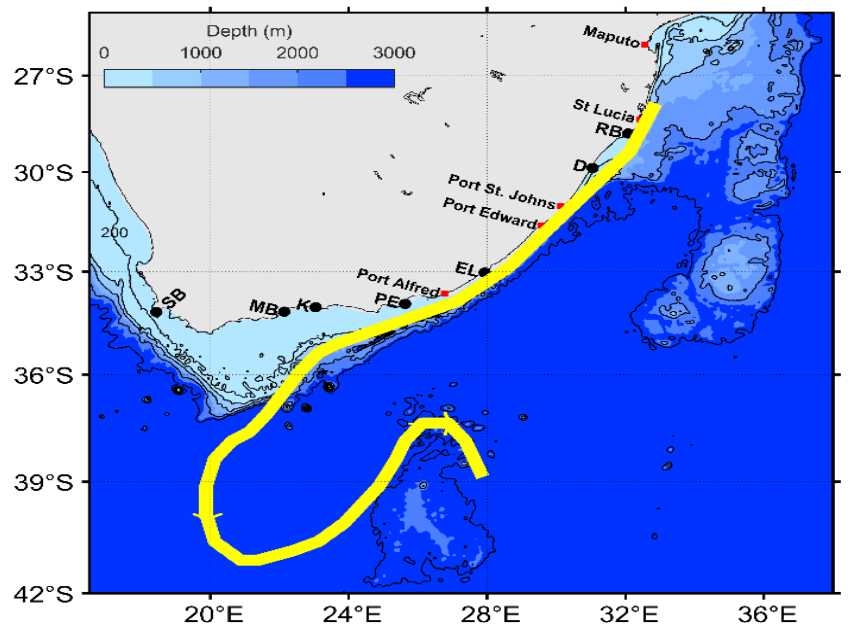

Figure 1. The location of tide gauge stations used in this study. RB, D, EL, PE, K, MB and SB indicate Richards Bay, Durban, East London, Port Elizabeth, Knysna, Mossel Bay and Simon's Bay tide gauges sites, respectively. Solid yellow line indicates the typical path of the Agulhas Current. 


\section{Data and Methods}

\subsection{Data}

To examine and advance the understanding of possible driving mechanisms of sea level variability, different datasets from several data sources were used. The details of each dataset used in this study are described below.

\subsubsection{Sea Level Observations}

Monthly mean sea level records of seven sites along the east and south coasts of South Africa, sourced from the Permanent Service for Mean Sea Level (PSMSL, [20]), are used in this study. These raw data has gaps that needed to be reduced or eliminated so that the analysis could give reliable conclusions. Hence, tide gauge measurements were combined with the gridded multi-mission Copernicus Marine and Environment Monitoring Service (CMEMS; www.marine.copernicus.eu, accessed on 10 April 2021) sea level satellite altimetry observations product, from January 1993 to December 2015, as described in Nhantumbo et al. [17].

\subsubsection{Large-Scale Oceanographic and Climate Data}

Several datasets were analysed to identify and evaluate the drivers of sea level variability and trends, including atmospheric and climate forcing. These are described below.

\section{Sea Level Pressure}

Monthly mean gridded reanalysis sea level pressure (SLP) from the National Centre for Environmental Prediction/National Centre for Atmospheric Research (NCEP/NCAR; [21]), downloaded from the webpage www.esrl.noaa.gov/psd/data/gridded/data.ncep.reanalysis. derived.html, accessed on 21 April 2021, were used. The global resolution is 2.5 degrees in both latitude and longitude directions, the unit is Pascals (Pa), and data are available from January 1948 to the present. The global data were used to study the large- and regional-scale relationships between SLP and regional sea level variability. In addition to this, the same monthly gridded SLP datasets were extracted at the nearest tide gauge location grid point to correct for the inverse barometer (IB) effect of the sea level records.

Winds

The monthly mean gridded reanalysis $10 \mathrm{~m}$ winds and wind stress also from the NCEP/NCAR [21] (www.esrl.noaa.gov/psd/data/gridded/data.ncep.reanalysis.derived. html, accessed on 10 August 2021) are used to investigate the large- and regional-scale relationships between wind and regional sea level variability. The gridded zonal and meridional components of the $10 \mathrm{~m}$ winds and wind stress are available on a T62 Gaussian grid and provided from January 1948 to the present, in meters per second (m/s) and Newton per square metre $\left(\mathrm{N} / \mathrm{m}^{2}\right)$, respectively.

Extended Reconstructed Sea Surface Temperature

Gridded monthly mean Extended Reconstructed Sea Surface Temperature (ERSST) version 4 [22] from the National Oceanic and Atmospheric Administration (NOAA) is used to investigate the large-scale relationships between SST and regional sea level variability. These data are provided globally at a 2-degree resolution in both latitude and longitude, given in degrees Celsius $\left({ }^{\circ} \mathrm{C}\right)$, and available from January 1854 to present from www.esrl. noaa.gov/psd/data/gridded/data.noaa.ersst.v4.html (accessed on 16 June 2021).

Dipole Mode Index

Time series of monthly mean Dipole Mode Index (DMI) [23], based on the NOAA ERSST, version 4, from January 1854 to present were used. Data are available at www. jamstec.go.jp/frcgc/research/d1/iod/e/iod/about_iod.html, accessed on 16 June 2021. The DMI is the main index used for monitoring Indian Ocean Dipole (IOD) conditions. DMI is derived from the SST difference between the south-eastern equatorial Indian Ocean 
(90-110 $\mathrm{E}$ and $\left.10^{\circ} \mathrm{S}-\mathrm{Equator}\right)$ and the western equatorial Indian Ocean $\left(50-70^{\circ} \mathrm{E}\right.$ and $\left.10^{\circ} \mathrm{S}-10^{\circ} \mathrm{N}\right)$. Previous studies [23-28] have indicated that the IOD has significant effects on the climate of the Indian Ocean rim countries, including the southern African region.

\section{Multivariate ENSO Index}

In order to investigate the possible influence of ENSO events on sea level variability, time series of monthly mean Multivariate ENSO Index (MEI) [29,30], from December 1949/January 1950 to present, were downloaded from www.esrl.noaa.gov/psd/enso/mei/ index.html, accessed on 16 June 2021. The MEI combines analysis of multiple meteorological and oceanographic components, including SLP, zonal and meridional components of the surface wind, SST, surface air temperature and total cloudiness fraction of the sky over the tropical Pacific. These observations have been collected and published in the International Comprehensive Ocean-Atmosphere Data Set (ICOADS, [31]). The MEI is considered to be the most complete index for ENSO monitoring and is derived twelve times per year for a 2-monthly moving average, corresponding to January-February, February-March, and so on. ENSO has been shown to impact climate over many areas of the world, including the southern African and South Indian Ocean region [32,33].

\section{Southern Annular Mode}

Time series of monthly mean Southern Annular Mode (SAM) data, from January 1957 to present, downloaded from https:/ / legacy.bas.ac.uk/met/gjma/sam.html, accessed on 16 June 2021, were utilised in this study. Also known as the Marshall Southern Annular Mode index [34], this index is derived from the difference between the zonal pressure at the stations located at $40^{\circ} \mathrm{S}$ and $65^{\circ} \mathrm{S}$. SAM modulates the westerly wind belt over the Southern Ocean. Given that SAM is known to impact the strength and position of cold fronts, it influences the weather and climate of the Southern Hemisphere south of about $20^{\circ} \mathrm{S}$, including southern Africa [35,36]. Positive SAM events reflect a poleward contraction of the belt of strong westerly winds resulting in fewer or weaker cold fronts reaching the southern part of South Africa. During negative SAM phases, the belt of strong westerly winds expands equatorward, causing more cold fronts to reach South Africa.

\subsection{Methods}

Outliers were removed from the monthly sea level data using a threshold of 3 standard deviations. Empirical Mode Decomposition analysis [18,19] was applied to separate the embedded timescales within the various time series analysed in this study. The EMD analysis is especially devoted to non-stationary and nonlinear time series. The method is a combination of Hilbert spectral analysis and EMD [18,37]. With this method, any time series data can be decomposed into a finite number of oscillatory modes, namely, intrinsic mode functions (IMFs) with time-variable amplitudes and frequencies. The Hilbert-Huang Transformation (HHT) identifies each IMF, and then the EMD decomposes them via a sifting process $[18,37]$ following the equation:

$$
Z_{(t)}=\sum_{j=1}^{N} C_{j(t)}+R_{(t)}
$$

where $Z_{(t)}$ is the original time series, $C_{j(t)}$ is the number of IMFs within the original time series and $R_{(t)}$ is the residual trend. Mode zero (0) is defined as the original time series and modes $1-\mathrm{N}$ are the oscillatory modes.

The number of cycles or modes is determined by the record length. The shape of each separated mode and, hence, the trend cannot be known in advance as the method is non-parametric [38,39]. Additionally, the trend is neither linear nor quadratic [18,37]. To confirm a relationship with a possible driving mechanism, one can undertake a single regression analysis by correlating each separated EMD mode, bearing in mind that the sea 
level modes and trend can be predicted from the forcing mechanism, for instance, regional sea level pressure EMD modes following the relation:

$$
Y_{i(t)}=a_{i} C_{i(t)}+b_{i}
$$

where $a_{i}$ and $b_{i}$ are the regression coefficients. Low-frequency EMD modes are similar to low-pass filtered time series.

The Ensemble Empirical Mode Decomposition (EEMD) analysis [40], with an ensemble mean of 100 EMDs and white noise as $10 \%$ of standard deviation, was used to eliminate artificial low-frequency modes. Then, the separated timescales of both sea level variability and drivers are combined to form the sub-annual and interannual timescale. The subannual timescale is the sum of the modes with a periodicity shorter than approximately one and a half years. The modes with a periodicity longer than approximately two years are summed to compute the interannual timescale.

The long-term linear trend and the seasonal cycle of each time series in this study were removed before analysis. Unless specified otherwise, a two-sided $t$-test was undertaken to test the significance, at $95 \%$ confidence level, of the correlations between the modes of the tide gauge sea level and atmospheric surface fields on a regional scale. Linear correlations (at various lags) were used to examine whether there is a possible connection between the modes of climate variability (IOD, ENSO and SAM) and coastal sea level variability along the south and east coasts of South Africa. The statistical significance of the resultant correlation coefficients was tested based on Huang et al. [41], at 5\% significance intervals. Given that regular correlations often include noisy and weak anomalies, composite analysis was also undertaken to get more insight into the connection between different forcing mechanisms and coastal sea level variability through stronger signals. The regression of modes of climate variability onto the local winds and sea level was used to better explain the processes contributing to the coastal sea level variability on the interannual timescale.

\section{Results}

\subsection{Drivers of Tide Gauge Sea Level Variability at Sub-Annual Timescales}

Figure 2 illustrates the correlation between tide gauge sea level variability and regional gridded SLP on sub-annual timescales. The highest correlation (largest in absolute value and negative) is found offshore. Thus, high sea level at the coast is linked with low SLP values over the open ocean. It is also evident that the offshore correlation values are higher on the south coast, between East London and Simons Bay, which may reflect the fact that this region and its offshore ocean, being further south than the east coast, experience a greater number of midlatitude weather disturbances. Since sea level records were corrected for the inverse barometer (IB) effect and the linear trend as well as the seasonal cycle were removed in both datasets, the effect of static pressure is removed. Consequently, the correlation with coastal sea level variability illustrated here may be explained in terms of its interaction with wind variations associated with the passing weather systems.

In order to understand the effect of the wind on coastal sea level variability, $\mathrm{u}-$ and vcomponents of the wind were examined separately. Figure 3 shows the correlation between regional $10 \mathrm{~m}$ zonal winds and sea level variability. In fact, the wind correlation appears to be strong near the coast, which is consistent with Figure 2. Overall, positive zonal winds (westerly winds) are associated with a high sea level at all tide sites under consideration. As a result, when sea level is high at the tide gauge and vicinity, the zonal wind is also high along the coast. This positive correlation suggests that the zonal component of the winds is associated with westerlies on this timescale. However, zonal winds seem to not have a significant association with sea level variability at Simons Bay (Figure 3g). Simons Bay lies on the eastern side of the Cape Peninsula below relatively high mountains to its west and south/southeast so that it is relatively sheltered from prevailing westerly winds in winter or southeasterly winds in summer, and so the relationship with the zonal wind at this station may be masked. With the exception of Simons Bay, the results also suggest that the impact of the zonal wind on coastal sea level variability is high on the south coast. 
(a) SLP vs TG at RB

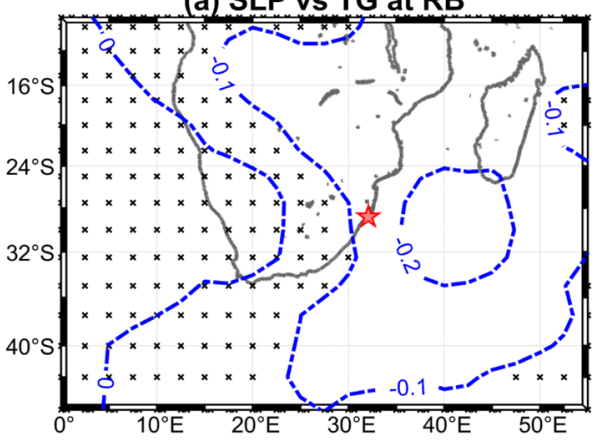

(c) SLP vs TG at EL

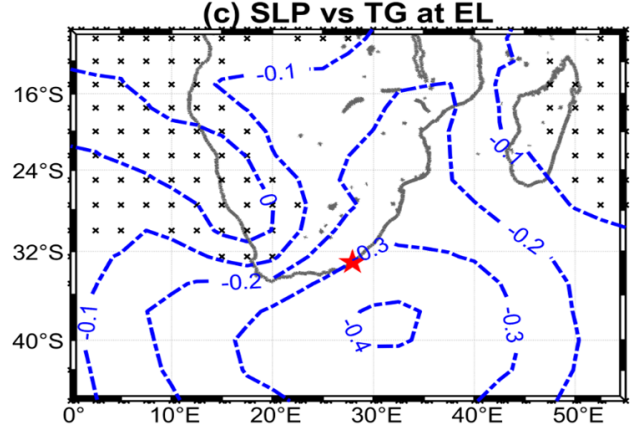

(e) SLP vs TG at K

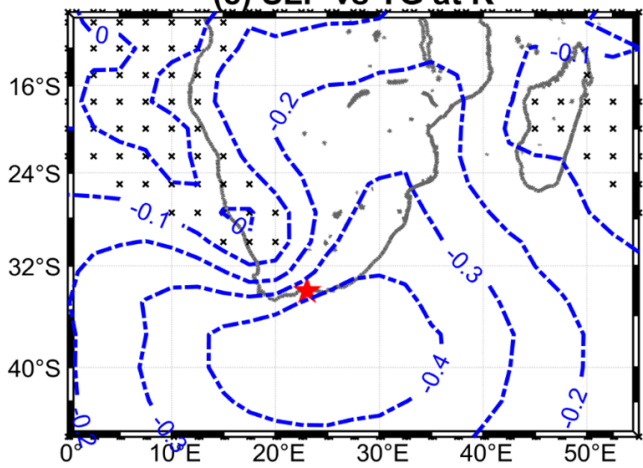

(b) SLP vs TG at D

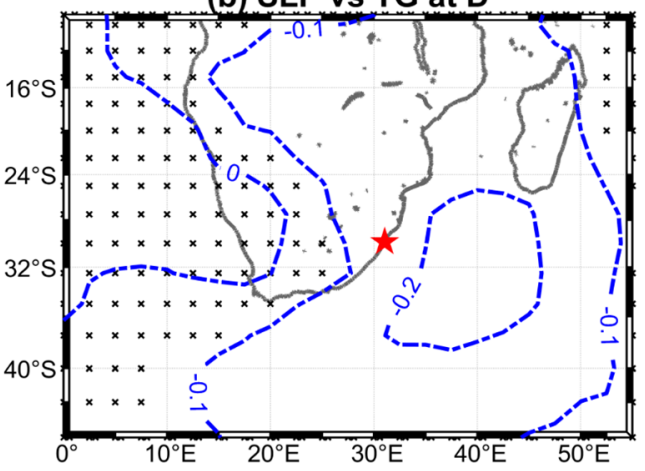

(d) SLP vs TG at PE

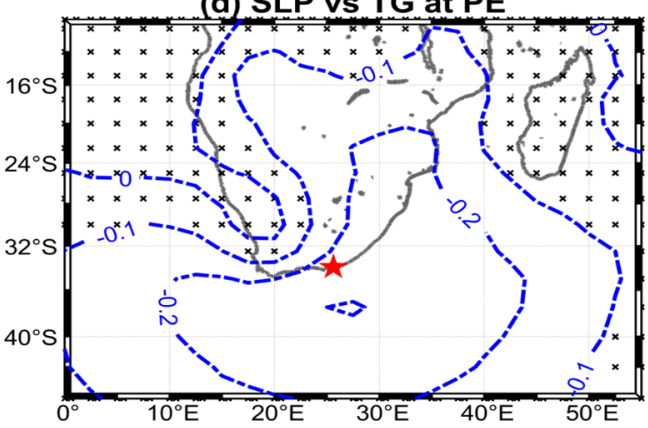

(f) SLP vs TG at MB

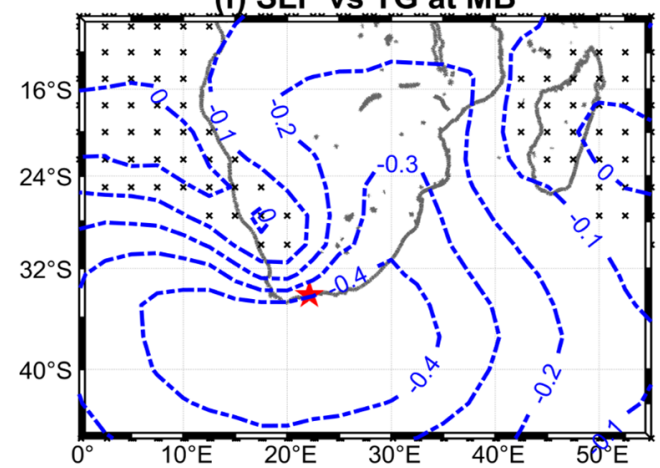

(g) SLP vs TG at SB

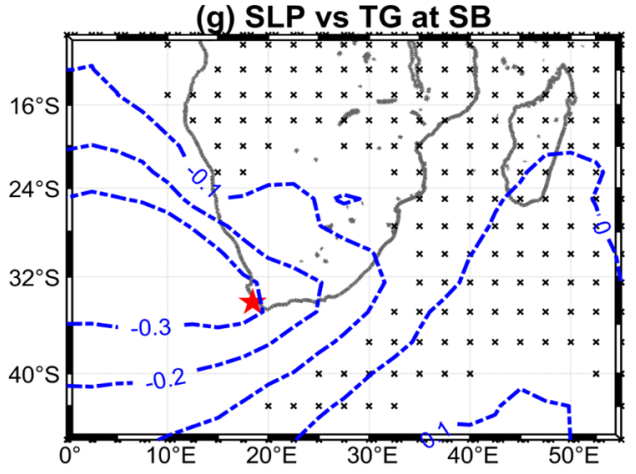

Figure 2. Correlation, on the sub-annual timescale, between regional gridded monthly mean SLP and monthly mean SL records at (a) Richards Bay, (b) Durban, (c) East London, (d) Port Elizabeth, (e) Knysna, (f) Mossel Bay and (g) Simons Bay, respectively. Red stars indicate the tide gauge location. Black crosses indicate areas statistically non-significant at $95 \%$ confidence level, estimated using a two-sided $t$-test. 

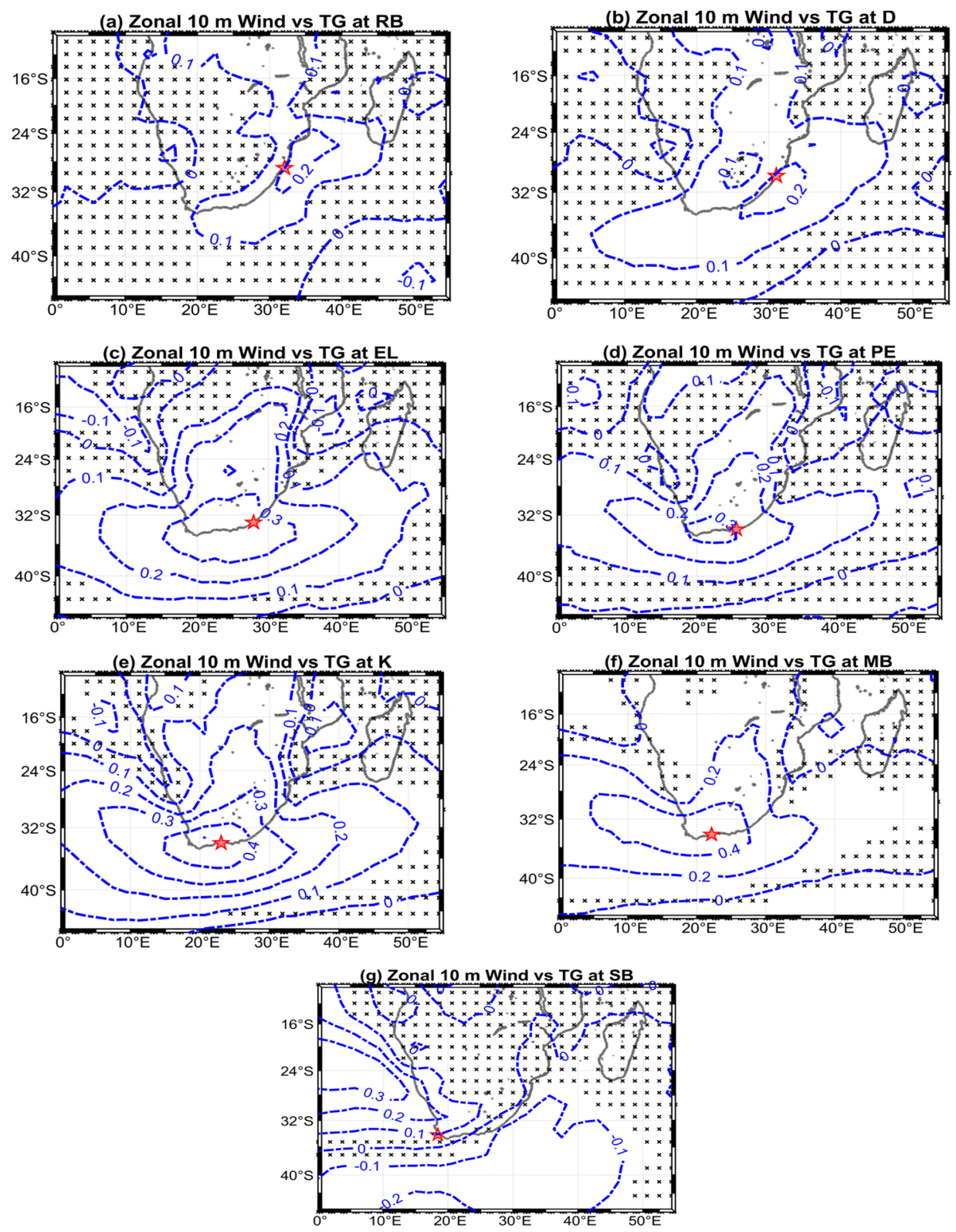

Figure 3. Correlation, on the sub-annual timescale, between regional gridded monthly mean zonal wind at $10 \mathrm{~m}$ above the mean sea surface and monthly mean sea level records at (a) Richards Bay, (b) Durban, (c) East London, (d) Port Elizabeth, (e) Knysna, (f) Mossel Bay and (g) Simons Bay, respectively. Red stars indicate the tide gauge location. Black crosses indicate areas statistically non-significant at $95 \%$ confidence level, estimated using a two-sided $t$-test.

Figure 4 displays the correlation between regional $10 \mathrm{~m}$ meridional wind and sea level variability on the sub-annual timescale. Positive meridional winds (southerly winds) are associated with high sea level at Richards Bay and Durban tide gauge locations (Figure 4a,b). However, at Knysna, Mossel Bay and Simons Bay, it is the negative meridional component of the wind (northerly winds) that is associated with high coastal sea levels (Figure $4 \mathrm{e}-\mathrm{g}$ ). Neither positive nor negative meridional winds seem to have a significant correlation with sea level at East London and Port Elizabeth (Figure 4c,d). The sea level at Knysna and Mossel Bay (Figure 4e,f), and less strongly Port Elizabeth and Simons Bay (Figure 4d,g), seems to have a good correlation with the meridional wind to the west of the station. It is noticeable that Richards Bay and Durban, East London and Port Elizabeth, and Knysna and Mossel Bay exhibit similar correlation patterns. Comparing Figures 3 and 4 may indicate that the zonal winds have a stronger relationship with sea level than the meridional 
winds. Thus, the results suggest that the midlatitude westerlies are the main wind driving mechanism of sea level variability on this timescale, especially on the south coast.
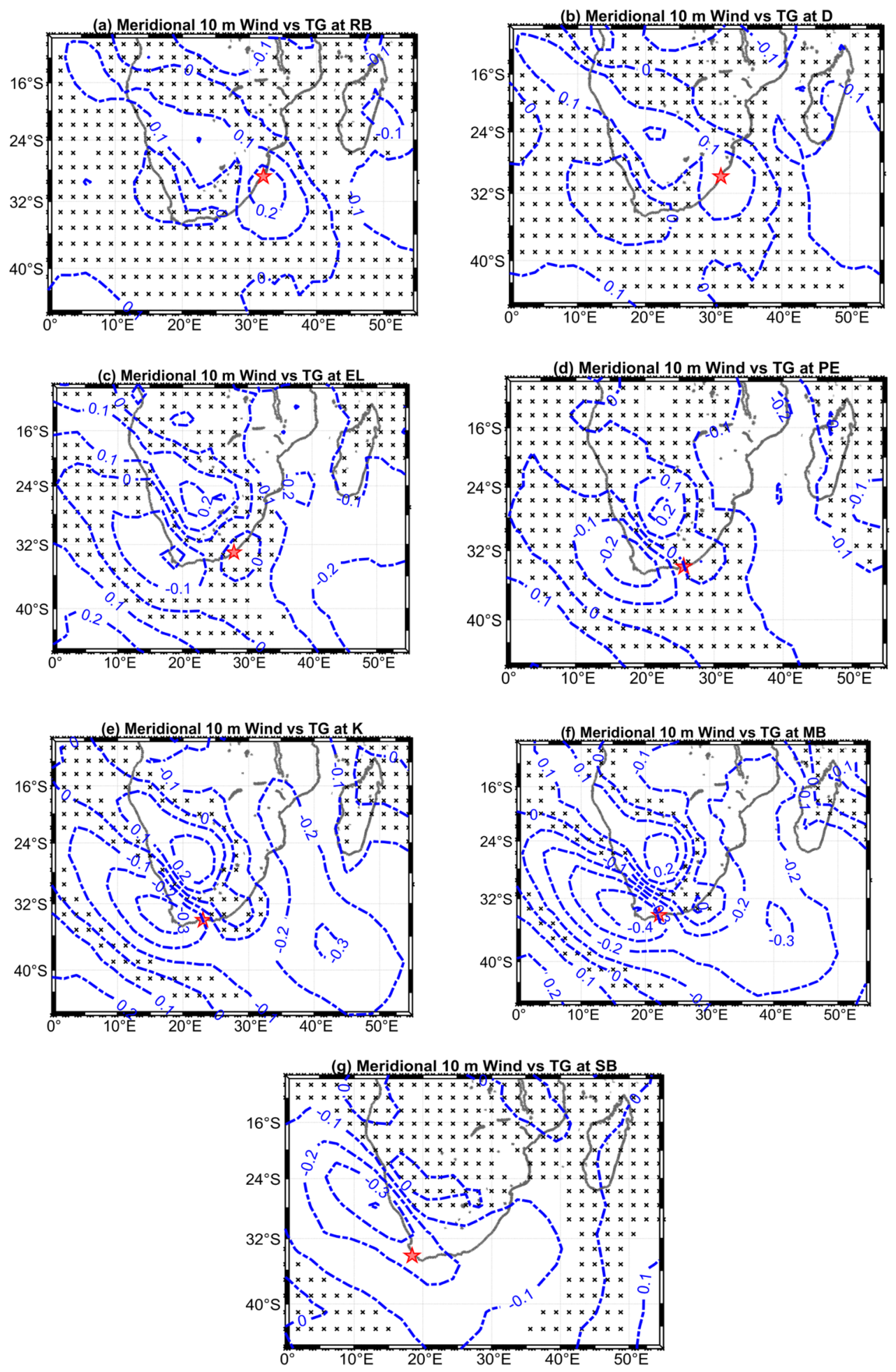

Figure 4. Correlation, on sub-annual timescale, between regional gridded monthly mean meridional wind at $10 \mathrm{~m}$ above the mean sea surface and monthly mean SL records at (a) Richards Bay, (b) Durban, (c) East London, (d) Port Elizabeth, (e) Knysna, (f) Mossel Bay and (g) Simons Bay, respectively. Red stars indicate the tide gauge location. Black crosses indicate areas statistically non-significant at $95 \%$ confidence level, estimated using a two-sided $t$-test. 
It should be noted, however, that given the correlation values in Figures 2-4, winds do not explain $100 \%$ of the variability on the sub-annual timescale. Nevertheless, the analyses contribute significantly to an improved understanding of the effect of atmospheric forcing on this timescale. How sea level along the east and south coasts of South Africa responds to mesoscale and synoptic weather systems is discussed in the next section.

\section{The Response of Coastal Sea Level to Strong Anomalies in the Atmospheric Forcing}

To further understand how mesoscale and synoptic weather systems are associated with coastal sea level along the east and south coasts of South Africa in the annual cycle, composite average differences between high and low sea level events were calculated and mapped using a one-and-a-half standard deviation threshold (Figure 5). Composite analysis focuses on the stronger signals and may give a clearer picture than the regular correlations, which include the often-noisy, weak anomalies. The colour scale on the right panels of Figure 5 show the SLP differences during high and low sea level events, while the vectors indicate the corresponding change in the direction and magnitude of the winds at $10 \mathrm{~m}$. It is noticeable that, except for Simons Bay (Figure $5 \mathrm{~g}$ ), the common pattern is a negative SLP difference south of South Africa, reflecting increased mid-latitude cyclonic conditions. As a result, a strong pressure gradient and northwesterly to northerly wind anomalies are found along the south coast, becoming more easterly near Durban and Richards Bay, whereas for Simons Bay the pattern is to the southwest of the country while there are anticyclonic wind conditions over most areas inland.

The relationships between regional atmospheric forcing and sea level variations along the South African coast, although mentioned in previous studies, are not yet understood. Limitations of data, in particular, have presented great problems in previous studies. Due to this poor data quality, the conclusions in many earlier studies were based solely on visual correlations and the apparent consistency of the results derived in this way with those conducted elsewhere around the globe $[2,7,12]$.

\subsection{Drivers of Tide Gauge Sea Level Variability on Interannual Timescales}

Figure 6 shows the correlation between the DMI and tide gauge sea level data, on the interannual timescale. The results suggest varying degrees of influence of IOD over the studied region, with correlations only at Durban and Port Elizabeth being statistically significant. The highest correlation values of approximately 0.36 and 0.24 are noted at Durban and Richards Bay, respectively. At both tide gauge sites, the coherence in the variability of sea level and the DMI is also noticeable. This suggests that the IOD has an influence on sea level variability on the east coast. At Port Elizabeth, there is also a correlation of -0.5 at 6 months lag. There are, on occasion, strongly positive or negative IOD events that co-occur with anomalously high/low sea level events. Despite there not being a consistently strong relationship between sea level and the IOD, as shown by the correlation with DMI, the 1997 positive IOD event, regarded as one of the strongest (e.g., [42]), appears to have led to positive sea level anomalies at all sites.

(a)

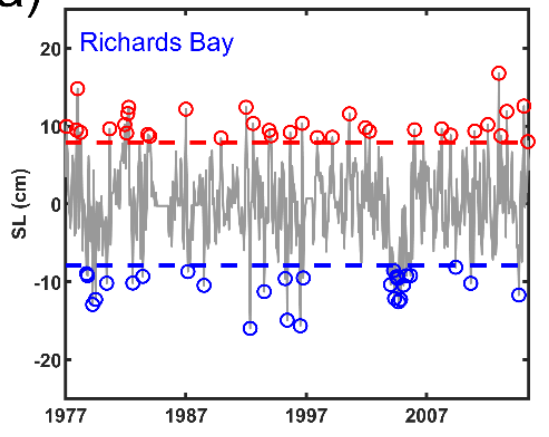

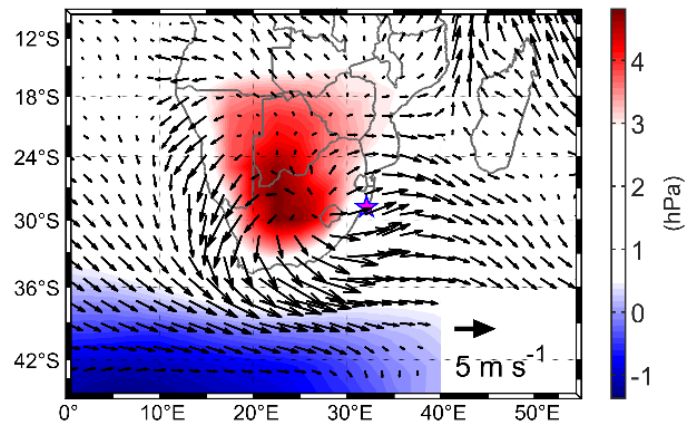

Figure 5. Cont. 
(b)

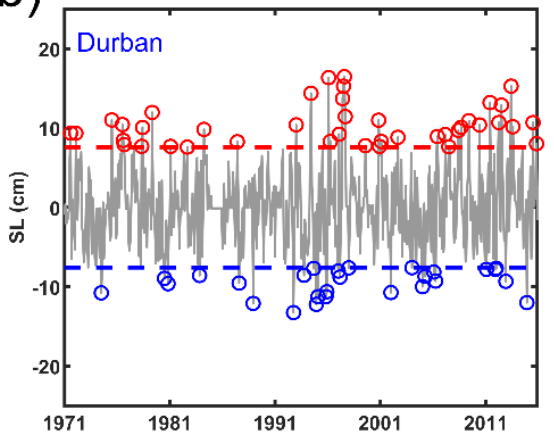

(c)

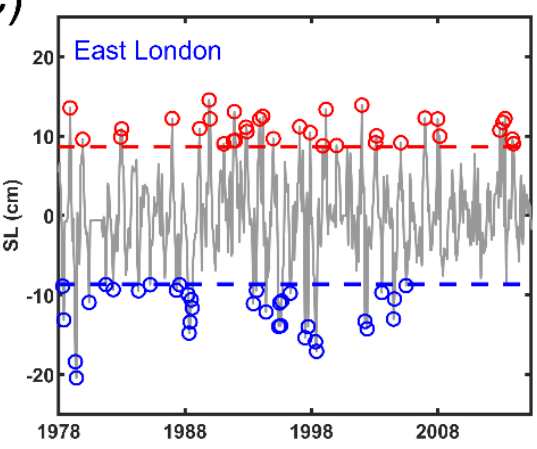

(d)

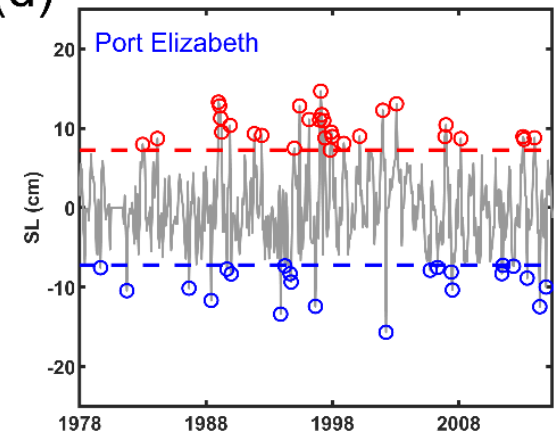

(e)

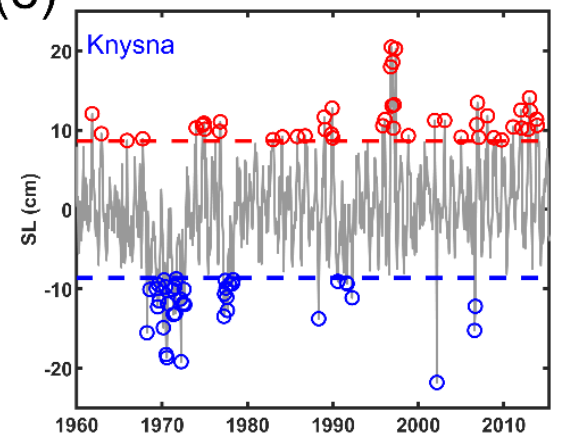

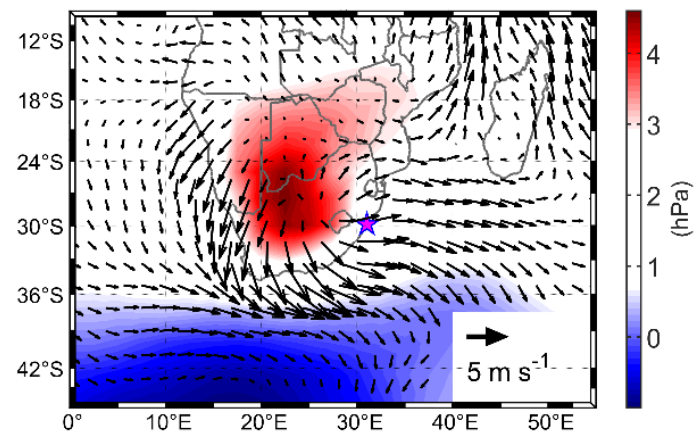
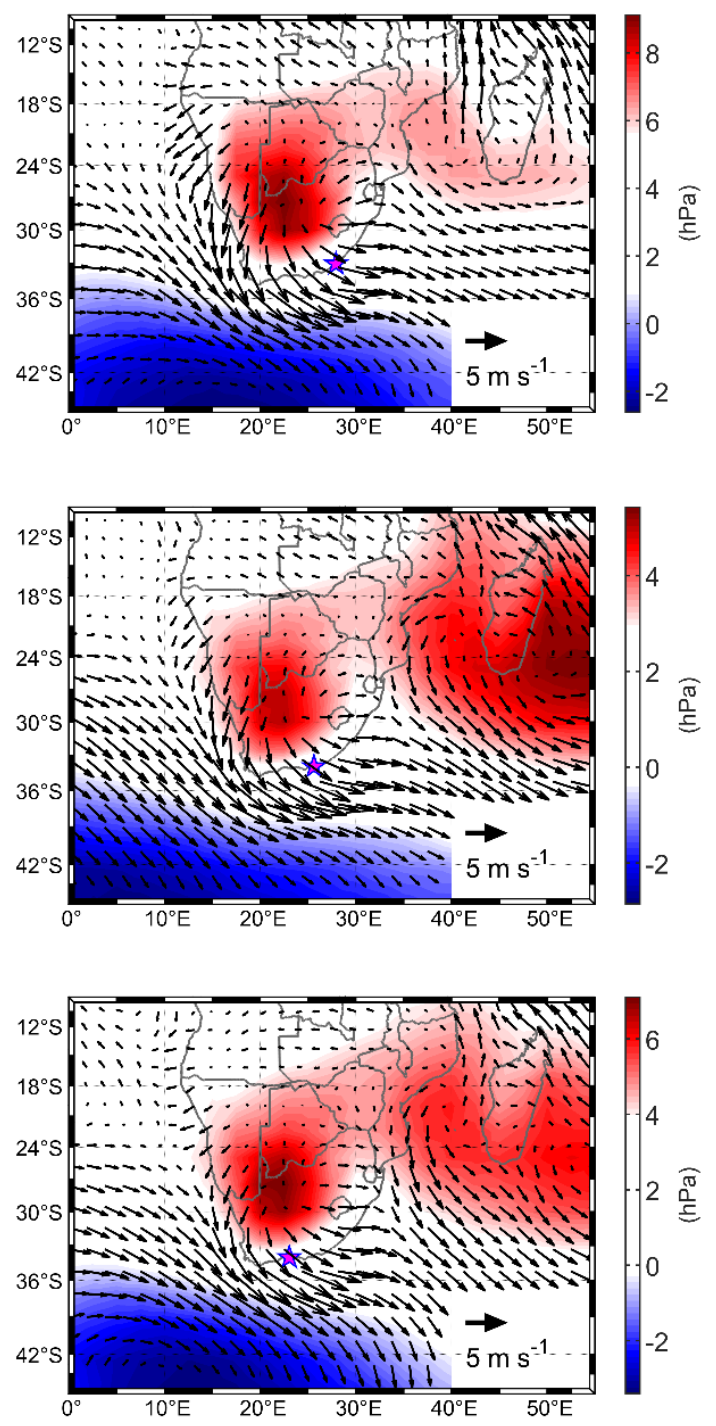

Figure 5. Cont. 

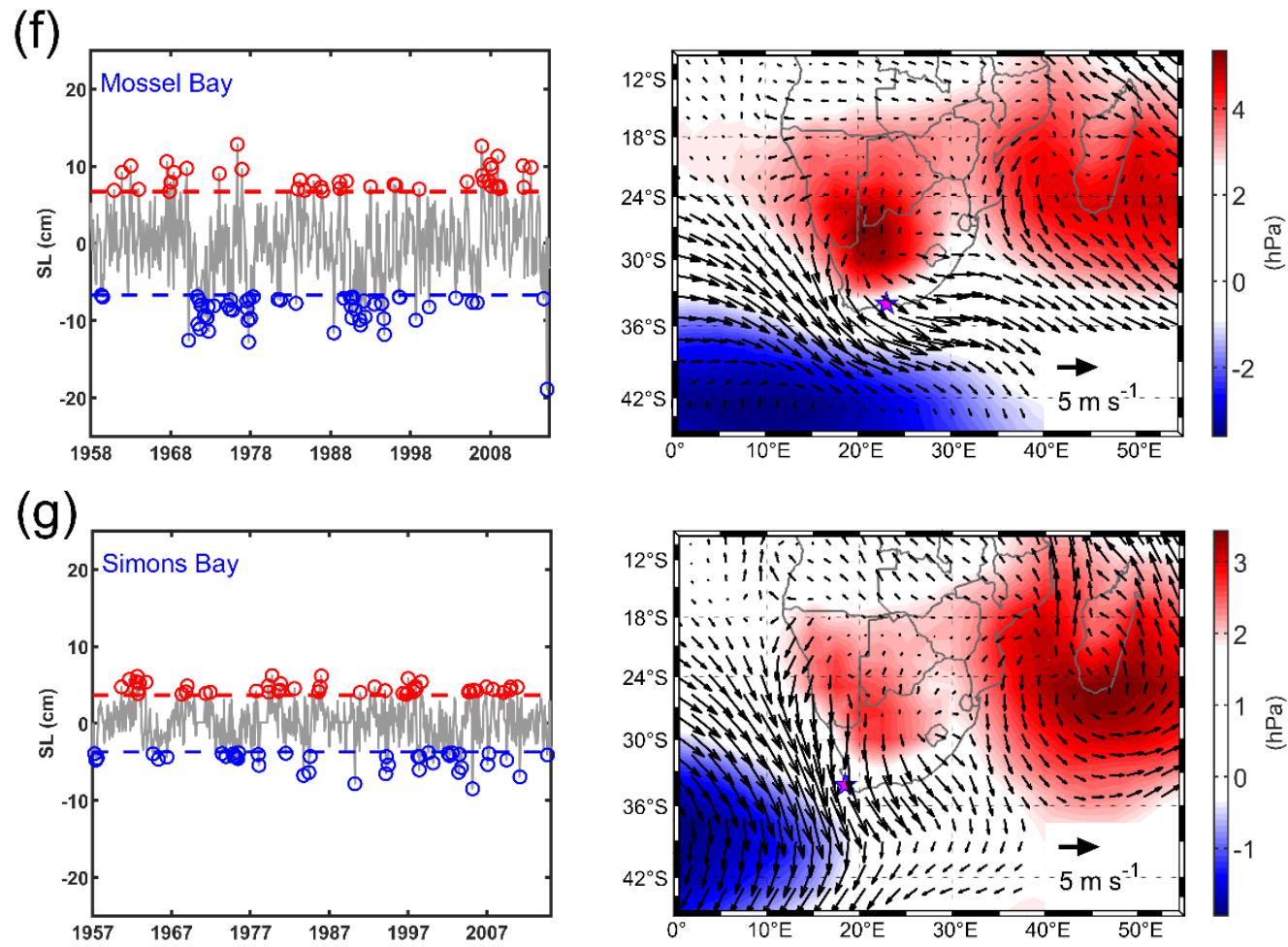

Figure 5. (Left) Monthly mean sea level, with high events ( $>1.5$ standard deviations, red circles) and low events $(<1.5$ standard deviations, blue circles) at different tide stations. (Right) Composite mean of the differences of the SLP (colour) and $10 \mathrm{~m}$ winds (vectors) corresponding to high and low events in the sea level at (a) Richards Bay, (b) Durban, (c) East London, (d) Port Elizabeth, (e) Knysna, (f) Mossel Bay and (g) Simons Bay, respectively. Magenta stars indicate the tide gauge location.
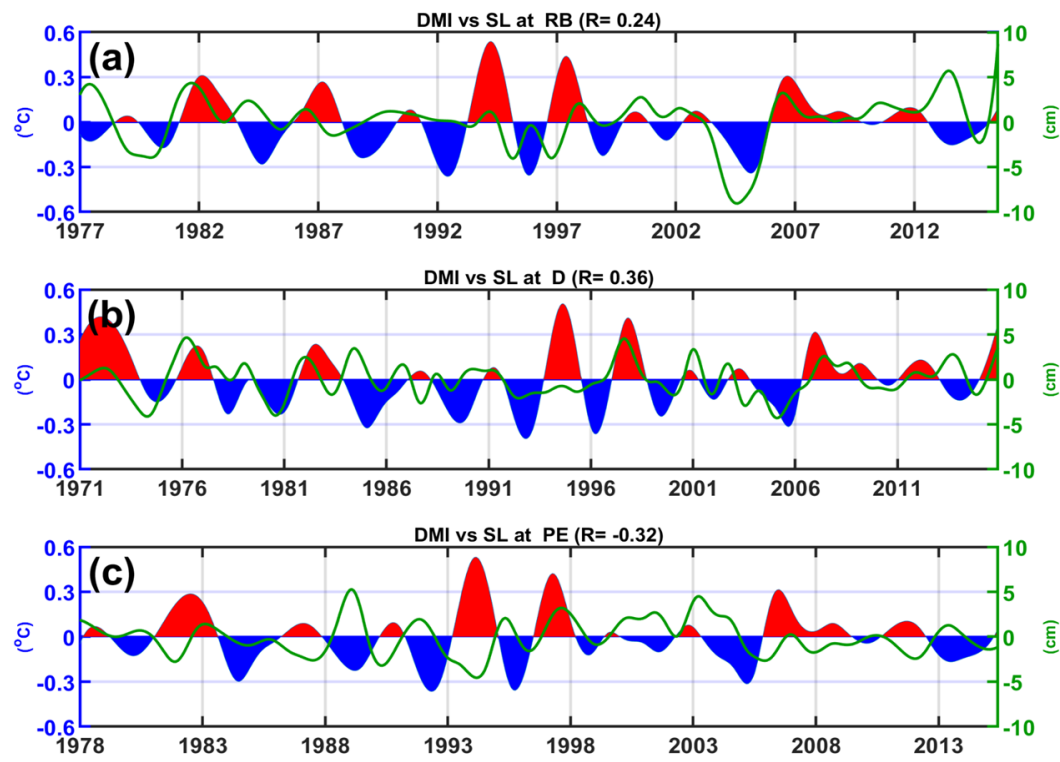

Figure 6. Time series of interannual Dipole Mode Index (DMI) and SL records at (a) Richards Bay, (b) Durban and (c) Port Elizabeth. DMI in degrees Celsius is given in blue and SL in centimeters is given in green. Correlation coefficients are found in the panel titles.

To further investigate the influence of climate indices, the correlation between MEI and sea level variability was examined. It is challenging to draw conclusions about consistent relationships based on interannual time series due to the inconsistent correlations and the 
lack of statistical significance even down to $90 \%$ confidence level. While the correlations between MEI and sea level at the various sites are very weak, the highest correlation was found at Durban, approximately 0.18 at 6 months lag (not shown). Figure 7 illustrates the correlation between the embedded timescales within monthly MEI and sea level records at East London, significant at 95\% confidence level. EMD modes 5, 6 and 7 indicate timescales of approximately 4-, 7- and 19-year periods, respectively. Overall, the longer-term modes have shown significant correlations between MEI and sea level at all studied tide sites. The mechanism through which the ENSO signal is transmitted to high/low sea levels is discussed later. However, Brundrit et al. [12] correlated the high sea level in the eastern South Atlantic to the strong 1982-1983 El Niño event.
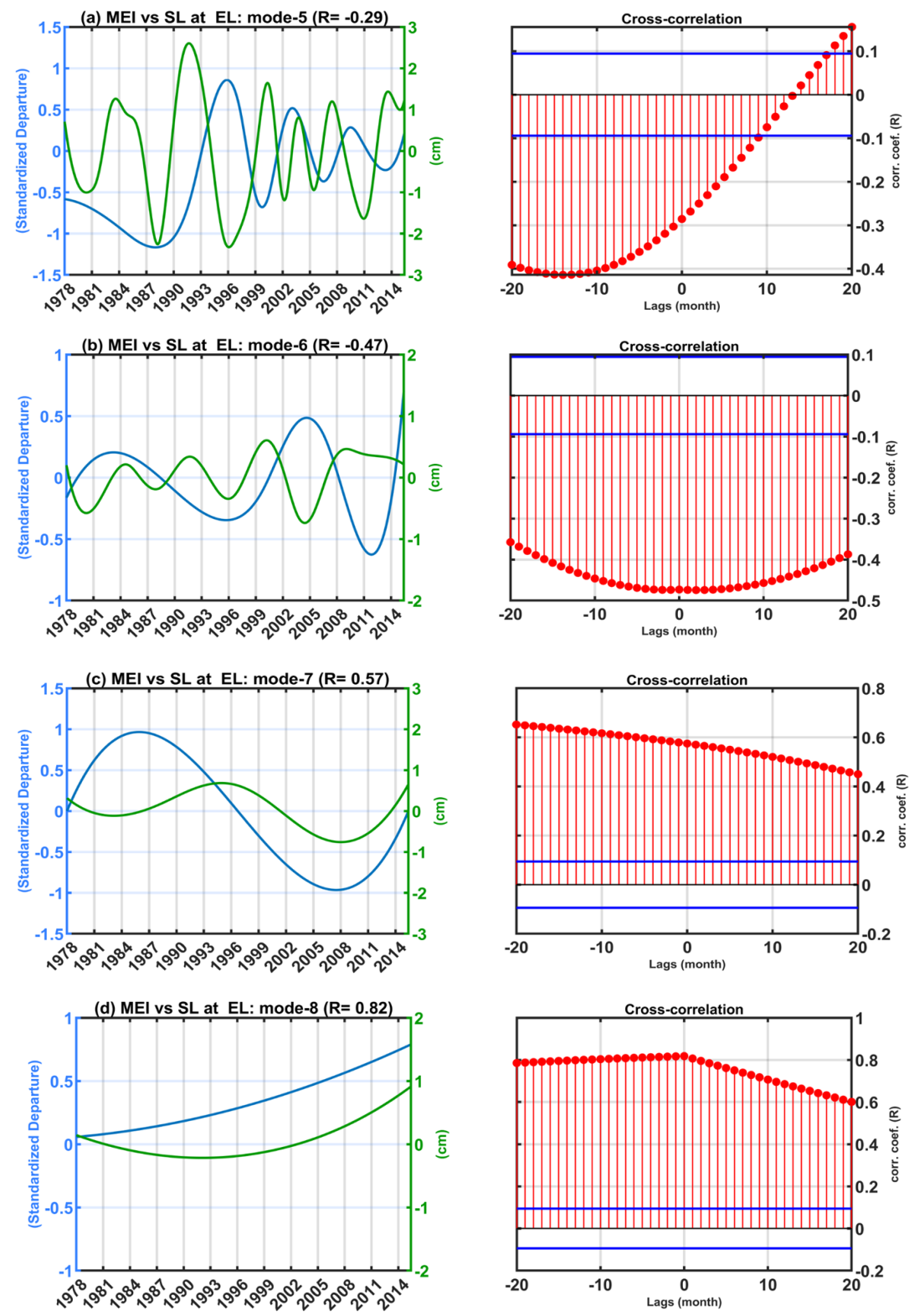

Figure 7. Correlation between monthly Multivariate ENSO Index and sea level at East London, on different timescales, separated by the EMD analysis. For a better comparison, the long-term linear trend and the seasonal cycle were removed from the original time series. Left panel, blue and green colours indicate the MEI and sea level (in centimeters), respectively. Right panel, the horizontal blue lines indicate the $95 \%$ confidence bounds. Mode 0 is the raw data, modes $1-7$ are the oscillating modes, and the remaining residual mode is the trend (mode 8). On average, modes 5, 6 and 7 represent approximately 4-, 7- and 19-year cycles, respectively. 
There are several ENSO indices, derived from different parameters including SLP and SST, although the choice was to use MEI due to its completeness, as described in the data section. To support this choice, other ENSO indices (Southern Oscillation Index (SOI) Niño 3.4) were also examined, and the results were comparable to the ones discussed above.

The correlation between SAM and sea level variability was also calculated (Figure 8). The results suggest that SAM has a measurable influence on coastal sea level in the region. The highest correlation value was found at Simon's Bay (approximately 0.25). The mechanism behind the SAM influence is explored further in this study based on regression analysis.

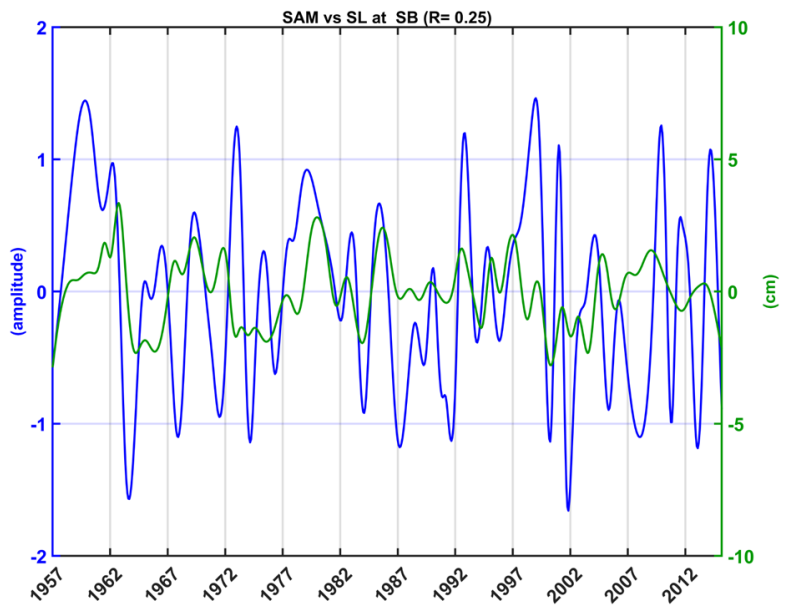

Figure 8. Time series of interannual Southern Annular Mode (SAM; [34], 2003) and SL records at Simons Bay. Blue and green colours indicate the SAM and SL (in centimeters), respectively. The correlation coefficient is found in the panel title.

The influence of the climate indices on sea level variability on the interannual timescale has been examined. The results suggest that, on this timescale, tide gauge SL variability is only weakly influenced by ENSO, IOD, and SAM. However, when analysing the embedded timescales within monthly climate indices and sea level records at all studied tide sites, only moderate relationships are found.

Thus, to understand the mechanism by which climate indices influence sea level variability on longer timescales, a regression of December-January-February (DJF) ENSO and SAM indices onto the local winds and sea level was performed and results are displayed in Figure 9. In general, the studied climate indices have significant regressions on winds along the studied coastal areas. This helps support the argument that there are climate indices influences on the local winds and hence sea level. The sub-season DJF was chosen based on literature (e.g., [33,36] for ENSO, [35,36] for SAM, [23,43] for IOD) suggesting December-January-February/January-February-March (DJF/JFM) as the seasons of maximum ENSO and SAM impact on the South African region. For IOD it is September-October-November (SON) or October-November-December (OND). 
(a)

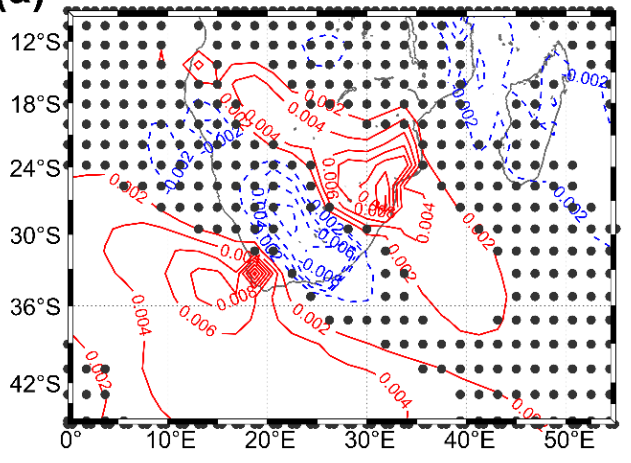

(c)

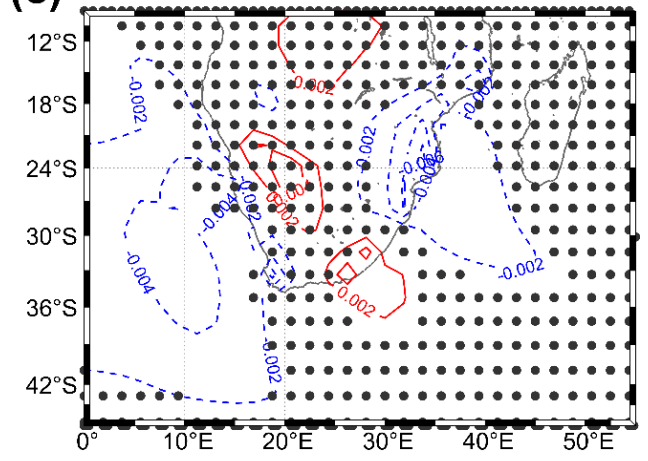

(b)

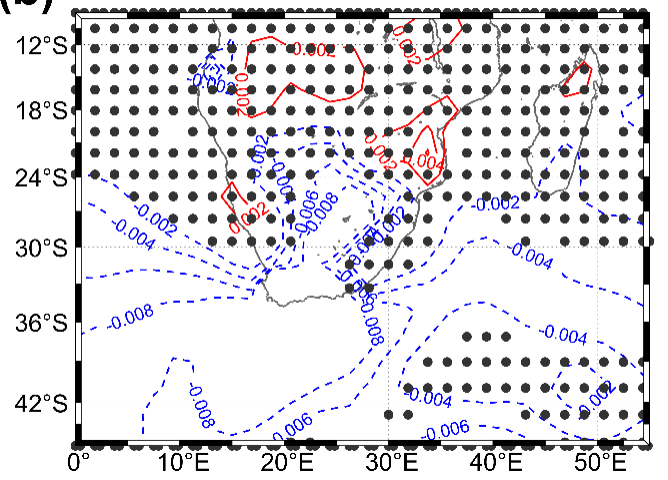

(d)

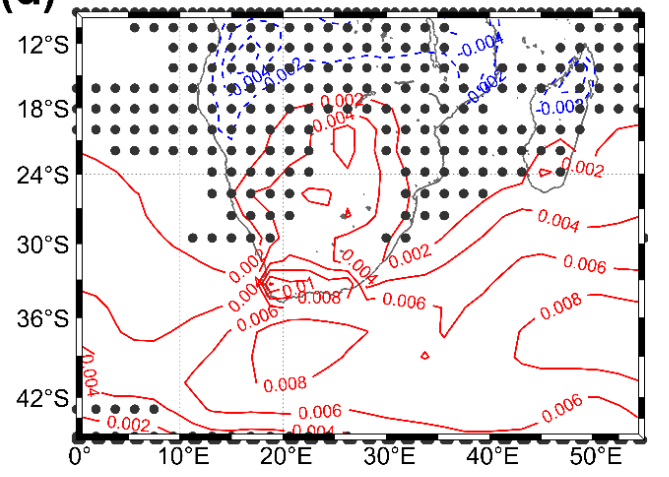

Figure 9. Regression coefficients of MEI onto (a) meridional wind stress and (b) zonal wind stress, and SAM onto (c) meridional wind stress and (d) zonal wind stress (DJF), respectively. The long-term linear trend was removed from the datasets. The base period for the analysis is 1960-2019. Dots indicate areas statistically non-significant at $90 \%$ confidence level based on $p$-value.

\section{The Combined Influence of the Modes of Climate Variability}

To further understand how the three modes of climate variability (ENSO, IOD and SAM) are associated with the coastal SL along the east and south coasts of South Africa on the interannual timescale, composite average differences between positive and negative (using 0.75 standard deviation threshold) MEI, DMI and SAM index events were calculated and the results are displayed in Figure 10. The colour scale shows the magnitude of the sea level differences during positive and negative events of ENSO, IOD and SAM, respectively. With the exception of East London, the resulting SL differences during ENSO events are statistically not significant. However, positive IOD events appear to force high coastal sea levels compared to negative IOD events. It appears that negative SAM events tend to induce higher coastal sea levels than positive SAM events. Figure 10 hardly indicates a pattern in the modulated SL differences that would help identify any sub-regional impacts over the studied region. It turns out, however, that East London displays a unique pattern, in agreement with the results discussed above [17].

Assuming that, for instance, a particularly positive or negative ENSO event may occur during months in which positive or negative IOD or SAM events are observed, the impact of the paired interaction between the three modes of climate variability and coastal SL was further investigated. Figure 11 shows the results of SL differences during the interaction of MEI-DMI, MEI-SAM and DMI-SAM, respectively. 


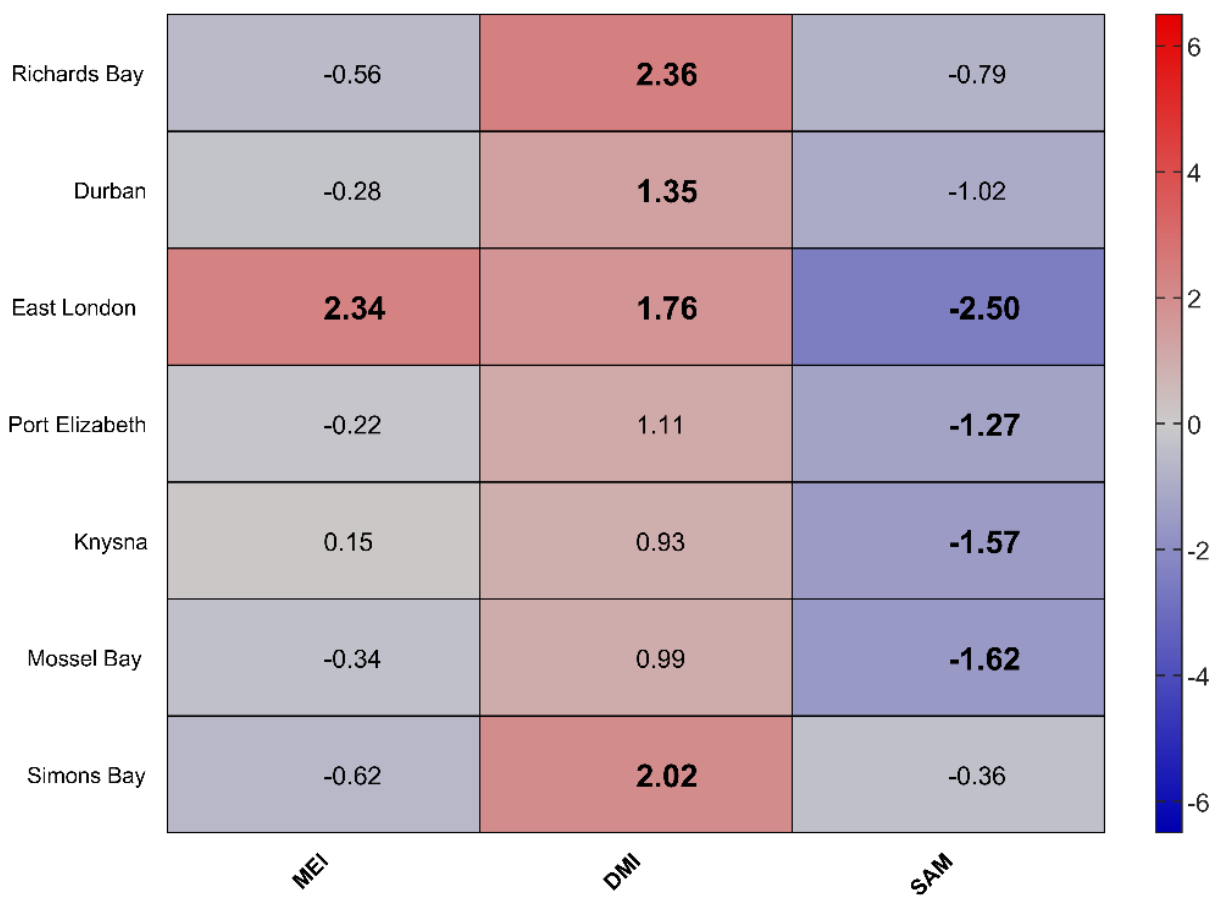

Figure 10. Sea level composite mean difference $(\mathrm{cm})$ based on MEI (ENSO), DMI (IOD) and SAM indices at all studied tide gauges. The tide gauges are labelled with their names ( $y$-axis), from east to south. Colour indicates the magnitude of SL differences during positive and negative indices. Numbers in bold are based on composite means that are significantly different above the $95 \%$ level, according to two sampled $t$-tests.

\begin{tabular}{|c|c|c|c|c|c|c|}
\hline Richards Bay & 1.94 & -1.79 & -0.28 & 0.92 & 3.00 & 1.59 \\
\hline Durban & 2.08 & -1.76 & -2.30 & 1.10 & 1.52 & 1.10 \\
\hline East London & 6.40 & 0.76 & 1.02 & 4.34 & -1.17 & 3.46 \\
\hline Port Elizabeth & 2.15 & -2.74 & -2.62 & 1.82 & 0.46 & -0.65 \\
\hline Knysna & 3.51 & -3.05 & -2.15 & 0.86 & -1.75 & 0.65 \\
\hline Mossel Bay & 0.50 & -3.48 & -0.58 & -0.13 & -2.08 & 1.74 \\
\hline Simons Bay & 2.88 & -6.15 & -0.73 & -2.67 & -0.24 & 2.68 \\
\hline
\end{tabular}

Figure 11. Sea level composite average differences $(\mathrm{cm})$ at all studied tide gauges, based on MEI/DMI, MEI/SAM and DMI/SAM climate mode combinations. The tide gauges are labelled with their names ( $y$-axis), from east to south. Colour indicates the magnitude of SL differences during the climate index combinations. Numbers in bold are based on composite means that are significantly different above the $95 \%$ level, according to two sampled $t$-tests. 
In general, the combinations +MEI/+DMI and +DMI/-SAM appear to modulate positive SL differences, implying that high coastal sea levels can be observed during months of El Niño and positive IOD or during positive IOD and negative SAM months, while low coastal sea levels appear to be more likely during months of El Niño and negative IOD or during El Niño and positive SAM. The strongest significant indications of these tendencies are the positive difference at East London during +MEI/+DMI and the negative SL difference at Simons Bay during +MEI/-DMI. During months of positive IOD and positive SAM (+DMI/+SAM), there is a good chance for high sea levels at Richards Bay in the east and low monthly sea levels at Mossel Bay in the south The same east to south response is indicated during +MEI/-SAM, with the strongest signals in East London and Simons Bay. (Note that the respective differences $3.0 \mathrm{~cm}$ at Richards Bay and $-2.67 \mathrm{~cm}$ at Simons Bay are significant above $94 \%$ ).

Furthermore, anomalously high sea level months (using one and a half standard deviations above the mean as a threshold) were identified (see Figure 5), and these events were plotted in the space of two climate indices (Appendix A). This may indicate how each tide gauge is influenced by a specific combination of the modes of climate variability (MEI/DMI, MEI/SAM and DMI/SAM). High and low sea level events were associated with wind changes to explain the atmospheric forcing. Here, the assumption is that those wind changes that result from the passage of mesoscale and synoptic weather systems may have been modulated by their interaction with the climate modes of variability and then affect coastal sea levels, which would be consistent with other studies (e.g., [44-47]) and Figure 9.

Overall, all the studied tide gauge sites (Figure A1) indicate that the interaction $+\mathrm{MEI} /+\mathrm{DMI}$ is likely to induce an anomalously high coastal sea level, consistent with the results of the sea level composite average differences discussed above (Figure 11). However, one cannot draw a sound conclusion regarding the pair of interactions that affects coastal sea level the most when examining the combinations of MEI and SAM indices during high sea level months at the studied tide gauge stations (Figure A2). Additionally, most of the studied tide gauge sites are dominated by the interaction +DMI/+SAM (Figure A3), which may indicate that there is a high probability for high sea levels to occur during the months of positive IOD/positive SAM events, not consistent with the results of sea level composite average differences.

To summarise, different combinations of the climatic modes of variability (MEI/DMI, MEI/SAM and DMI/SAM) were examined to further understand the impact of their interaction on local and regional coastal sea level. The results suggest a varying degree of influences, with East London displaying a unique connection as well as being the separation point for east and south effects [17].

\section{Discussion}

It is difficult to ascertain which driver is embedded in the data when interpreting each mode. Each timescale (or even mode) may represent one or more physical drivers. However, identifying a single driver for each separated timescale is challenging due to our limited knowledge of how sea level is linked to the various forcing mechanisms (e.g., [48]). A key question to consider is whether it is possible to determine a physical meaning for each timescale, or should the timescale isolated by EMD be determined according to the periodicity of known drivers?

Usually, the periodicities of drivers cover a range of timescales [23,34,49,50]. As a consequence, a driver may have a measurable effect over a set of single modes of SL variability. Thus, it would be better to combine some modes with different periodicities to identify physically meaningful ranges of frequencies to compare with known drivers. Therefore, at each tide gauge location, the separated oscillatory modes are grouped into sub-annual and interannual timescales of sea level variability. These temporal scales of sea level variability are considered to be physically more meaningful, and hence easier to relate to known drivers of atmospheric conditions and climate variability. 
On the sub-annual timescale, only atmospheric forcing was considered. This is because previous studies have indicated that the mesoscale and synoptic weather disturbances are the driving mechanisms of the southern Africa coastal sea level variability on this timescale, based on daily mean [5-9] and monthly mean [2,7] tide gauge records, respectively. Therefore, the time series at each studied tide gauge site were correlated with the time series at each grid point of the regional atmospheric data, and the statistical significance of the resultant correlation was estimated through a two-sided $t$-test.

Overall, there is a consistent positive SLP difference centered over the southern Africa sub-continent. Surface high-pressure systems are associated with a counter-clockwise (anti-cyclonic) wind circulation in the Southern Hemisphere and over the study region (e.g., [51-54]). The negative SLP difference over the Southern Ocean is notable, producing a north-south pressure gradient. The composite winds are consistent with the pressure pattern. As can be seen, as one moves from one station to the next, there is a consistent eastward displacement of the core of the positive SLP difference, resulting in a west-east pressure gradient, followed by the change in wind strength and direction.

The features displayed in Figure 5 are consistent with the correlations between regional SLP and $10 \mathrm{~m}$ winds, and the tide gauge SL variability discussed above; hence, such features point to the mechanism by which wind variations are associated with coastal sea level on a sub-annual timescale. The association between wind variations and coastal SL variability can be explained through Ekman transport dynamics $[47,55]$. Thus, wind variations (mainly longshore winds) induce an onshore water mass transport towards the tide gauge location, i.e., to the left of the wind direction in the Southern Hemisphere [55].

In summary, the results presented in Figure 5 suggest that SLP gradient anomalies cause enhanced alongshore winds leading to an increased or decreased coastal SL through Ekman transport dynamics, on the sub-annual timescale, suggesting that sea level responds to the mesoscale and synoptic weather systems in the annual cycle, in agreement with previous literature $[2,7,12]$. It turns out, however, that the response of coastal sea level variability to longshore wind variations associated with mesoscale and synoptic weather systems is commonly used to describe the propagation characteristics of coastal trapped waves along the coast of southern Africa on timescales of days [8,9]. Hence, when analysing Figure 5 from the south to the east coast, i.e., from Simons Bay to Richards Bay, one can notice that if a coastal trapped wave is generated on the west coast, it would travel anticlockwise to the east, in agreement with Chelton and Davis [56]. According to Chelton and Davis [56], the lagged response to the disturbances along the eastern boundary regions can also be detected in monthly mean tide gauge records.

Brundrit [2] suggested that the mesoscale and synoptic atmospheric disturbances are responsible for $5 \mathrm{~cm}$ of the variability in the monthly mean sea level data. These weather systems propagate from the west to south coast around southern Africa. The periodicity and amplitude of the sum of the sub-annual modes appear to confirm this. On the south coast, the amplitude of sub-annual timescale variability is around $5 \mathrm{~cm}$, consistent with the results of [2], along the west coast. In contrast to the south coast, the east coast, from Port Elizabeth equatorward, shows sub-annual amplitudes greater than $5 \mathrm{~cm}$. The causes of this increase in amplitude were not further investigated given the scope of this study.

The contribution of synoptic atmospheric disturbance patterns to the daily mean sea level amplitude is 30-50 cm around the southern African coast, allowing the study of propagation characteristics of coastal trapped waves [8,9]. Furthermore, the influence of the mesoscale and synoptic atmospheric disturbances as the drivers of sea level variability tends to be less important on longer timescales (e.g., [57]), but is not negligible (e.g., $[45,57,58])$.

Positive SAM events reflect a poleward contraction of the belt of strong westerly winds resulting in fewer low-pressure systems reaching southern Africa. Overall, negative SAM events may lead to high SL at Richards Bay, Durban, East London and Port Elizabeth, and positive SAM events may lead to high SL at Knysna, Mossel Bay and Simons Bay. 
The mechanism by which modes of climate variability are related to coastal sea level variability is yet not fully understood $[59,60]$. The consensus so far is that the climate indices do not influence coastal sea level directly; instead, they modulate the oceanic circulation patterns as well as the frequency and intensity of the various regional weather systems (Figure 9) that can directly affect coastal sea levels (e.g., [44-47]). This is in line with the results of DJF climate indices regressed onto local winds in Figure 9. The features displayed in Figure 9 suggest the mechanism by which climate indices induce coastal wind variations over the studied region and hence coastal sea level on an interannual timescale.

\section{Summary and Conclusions}

Monthly mean sea level records, at seven individual tide gauge locations, from the south and east coast of South Africa, were used to study the timescales of variability, their relationships to atmospheric forcing and modes of climate variability.

At the sub-annual timescale, sea level responds to regional zonal and meridional winds associated with mesoscale and synoptic weather disturbances in the annual cycle. These results are in agreement with previous studies [2,7,12]. It is hypothesised that through Ekman transport dynamics, SLP and longshore winds increase and decrease the coastal sea level on this timescale.

The results suggest a connection between coastal sea level variability and climate indices on the interannual timescale, although it is neither consistent across the set of tide stations nor particularly strong. This was supported by the examination of the regression of ENSO and SAM onto the local winds to get more insight into the processes contributing to the coastal sea level variability on an interannual timescale. Strong positive ENSO events tend to increase coastal SL, while strong negative ENSO events tend to decrease SL; however, the relationship is not consistent. Overall, strong IOD events tend to have a similar influence as the strong ENSO events. The results also suggest that, in general, negative SAM events may lead to high coastal sea level events. It was noticed that particularly strong ENSO and IOD events were in phase with sea level variability, which may be reinforcing the suggestion that climate indices could be related to coastal sea level variability via local wind modulation.

To further understand how the three modes of climate variability (ENSO, IOD and SAM) under consideration are associated with the coastal sea level on interannual timescales, composite average differences between positive and negative (using 0.75 standard deviation threshold) MEI, DMI and SAM events were calculated.

The combinations of MEI and SAM indices in months of anomalously high sea levels at the tide gauge stations under consideration prevented us from drawing a sound conclusion concerning the dominant interaction, suggesting a need for further analysis.

Given the results of this study, further investigations are necessary to understand the regional atmospheric circulation patterns associated with each binary interaction. This would help explain wind and pressure variation characteristics associated with specific combinations of the modes of climate variability and their effects on coastal sea level.

Overall, the results are in agreement with the linear correlations, suggesting that, in general, high monthly coastal sea levels are more likely during El Niño, positive IOD and negative SAM events, respectively. La Niña events appear to induce low monthly coastal sea levels at approximately similar magnitudes to El Niño events. It is worth highlighting that this offers some predictive capabilities to be explored by ocean modellers.

The impact of the paired interaction between the three modes of climate variability and coastal sea level in months with sea levels higher than 1.5 standard deviations above mean sea level were further investigated. The results suggest that the influence of climate variability on coastal sea level may be quantified through their binary interactions despite further investigation being necessary to substantiate the statement. Thus, in most of the locations, the likelihood of anomalously high coastal sea levels during months of El Niño/positive IOD and positive IOD/positive SAM events is fairly high. 
The results presented here suggest that, given their connections to coastal sea level variability, it is worth monitoring the patterns of mesoscale and synoptic weather disturbances and the modes of climate variability for better coastal planning, management and engineering.

Author Contributions: Conceptualization, methodology, B.J.N., B.C.B. and J.E.Ø.N.; software, data acquisition and processing, writing - original draft preparation, B.J.N.; validation, formal analysis, investigation, writing - review and editing, B.J.N., B.C.B., J.E.Ø.N. and C.J.C.R.; supervision, B.C.B., J.E.Ø.N. and C.J.C.R. All authors have read and agreed to the published version of the manuscript.

Funding: This research received no external funding.

Institutional Review Board Statement: Not applicable.

Informed Consent Statement: Not applicable.

Data Availability Statement: Data used here are freely available on the internet and the sources are indicated in the article and referenced in the reference list.

Acknowledgments: Financial support for this study was provided by the Nansen-Tutu Centre for Marine Environmental Research and the Applied Centre for Climate and Earth Systems Science (ACCESS) through funds sourced from the Nansen Scientific Society (NANSI) and the South African National Research Foundation (NRF).

Conflicts of Interest: The authors declare no conflict of interest or personal relationships that could have appeared to influence the work reported in this article. 


\section{Appendix A}
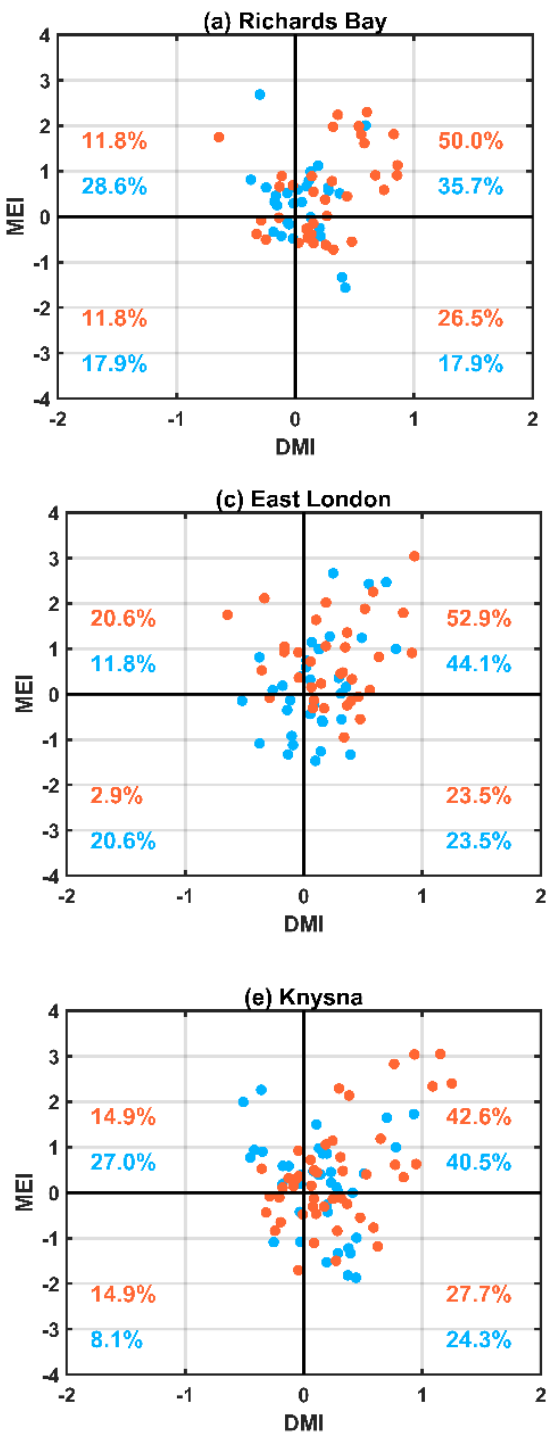
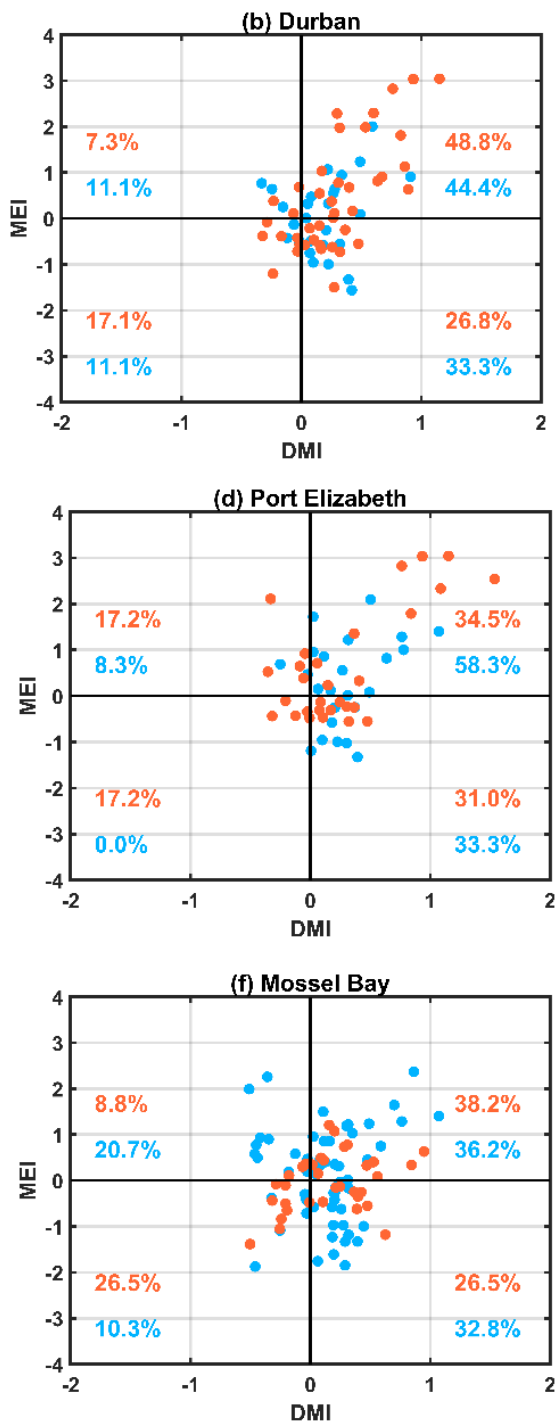

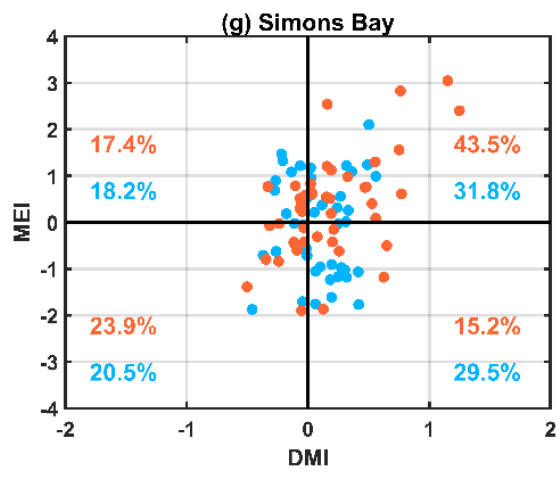

Figure A1. The MEI/DMI combinations in months with higher/lower (in red/blue) sea level than 1.5 standard deviations above/below mean sea level at (a) Richards Bay, (b) Durban, (c) East London, (d) Port Elizabeth, (e) Knysna, (f) Mossel Bay and (g) Simons Bay, respectively. The percentages indicate the number of months within a quadrant divided by the total number of the recorded SL months of the paired interactions. 

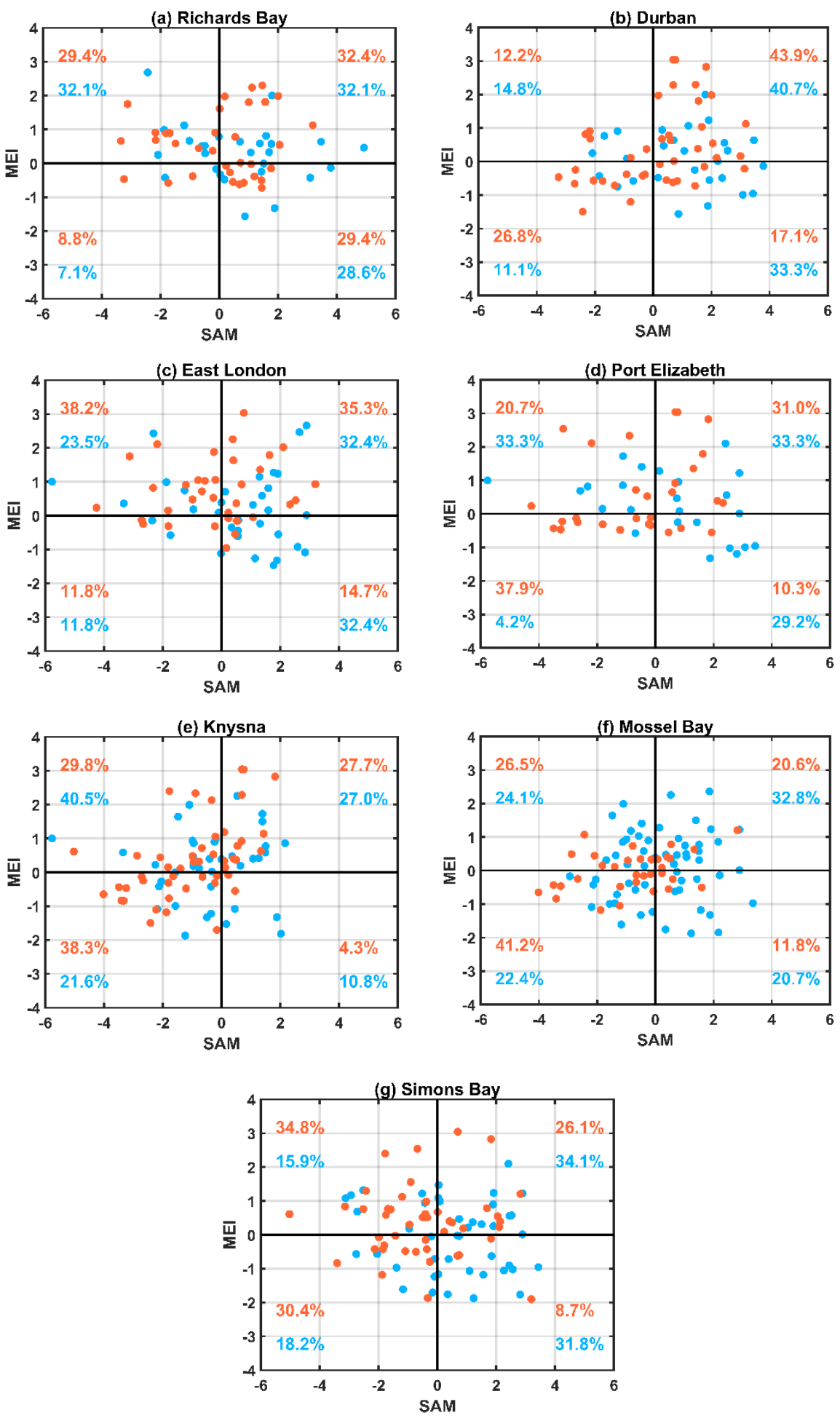

Figure A2. The MEI/SAM combinations in months with higher/lower (in red/blue) sea level than 1.5 standard deviations above/below mean sea level at (a) Richards Bay, (b) Durban, (c) East London, (d) Port Elizabeth, (e) Knysna, (f) Mossel Bay and (g) Simons Bay, respectively. The percentages indicate the number of SL months within a quadrant divided by the total number of the recorded SL months of the paired interactions. 

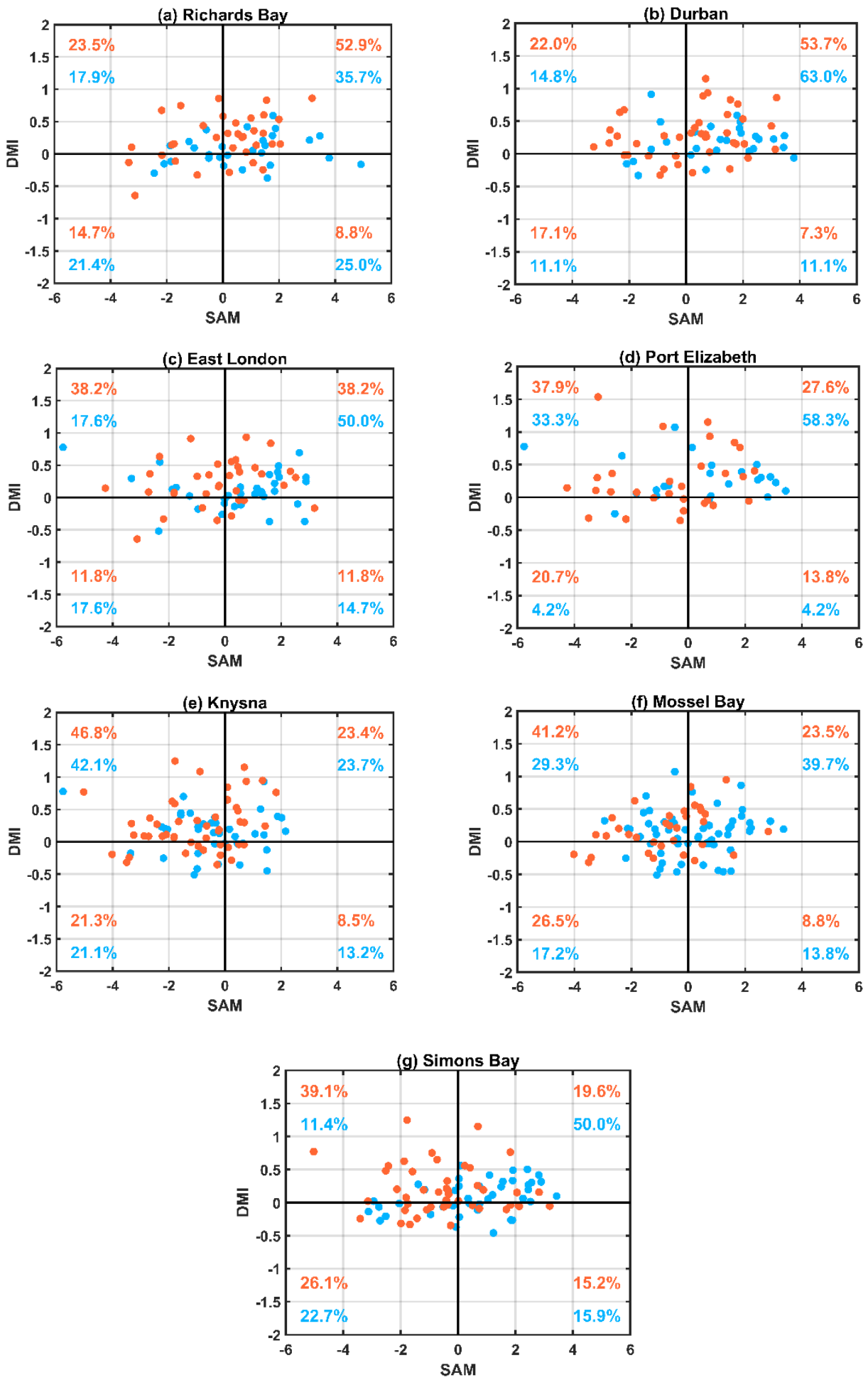

Figure A3. The DMI/SAM combinations in months with higher/lower (in red/blue) sea level than 1.5 standard deviations above/below mean sea level at (a) Richards Bay, (b) Durban, (c) East London, (d) Port Elizabeth, (e) Knysna, (f) Mossel Bay and (g) Simons Bay, respectively. The percentages indicate the number of SL months within a quadrant divided by the total number of the recorded SL months of the paired interactions. 


\section{References}

1. Mather, A.A.; Stretch, D.D.; Garland, G.G. Southern African sea levels: Corrections, influences and trends. Afr. J. Mar. Sci. 2009, 31, 145-156. [CrossRef]

2. Brundrit, G.B. Monthly Mean Sea Level Variability along the West Coast of Southern Africa. S. Afr. J. Mar. Sci. 1984, 2, 195-203. [CrossRef]

3. Brundrit, G.B. Trends of Southern African Sea Level: Statistical Analysis and Interpretation. S. Afr. J. Mar. Sci. 1995, 16, 9-17. [CrossRef]

4. Woodworth, P.L.; Aman, A.; Aarup, T. Sea level monitoring in Africa. Afr. J. Mar. Sci. 2007, 29, 321-330. [CrossRef]

5. Schumann, E.H. Low frequency fluctuations off the Natal coast. J. Geophys. Res. Oceans 1981, 86, 6499-6508. [CrossRef]

6. Schumann, E.H. Long-Period Coastal Trapped Waves off the Southeast Coast of Southern Africa. Cont. Shelf Res. 1983, 2, 97-107. [CrossRef]

7. Brundrit, G.B.; De Cuevas, D.; Shipley, A.M. Significant Sea-Level Variations along the West Coast of Southern Africa 1979-1983. S. Afr. J. Sci. 1984, 80, 80-82.

8. De Cuevas, B.A.; Brundrit, G.B.; Shipley, A.M. Low-frequency Sea-level Fluctuations along the Coasts of Namibia and South Africa. Geophys. J. R. Astron. Soc. 1986, 87, 33-42. [CrossRef]

9. Schumann, E.H.; Brink, K.H. Coastal-Trapped Waves off the Coast of South Africa: Generation, Propagation and Current Structures. J. Phys. Oceanogr. 1990, 20, 1206-1218. [CrossRef]

10. Reason, C.J.C.; Jury, M.R. On the generation and propagation of the southern African coastal low. Q. J. R. Meteorol. Soc. 1990, 116, 1133-1151. [CrossRef]

11. Weldon, D.; Reason, C.J.C. Variability of rainfall characteristics over the South Coast region of South Africa. Theor. Appl. Climatol. 2014, 115, 177-185. [CrossRef]

12. Brundrit, G.B.; De Cuevas, B.A.; Shipley, A.M. Long-term sea-level variability in the eastern South Atlantic and a comparison with that in the eastern pacific. S. Afr. J. Mar. Sci. 1987, 5, 73-78. [CrossRef]

13. Colberg, F.; Reason, C.J.C.; Rodgers, K. South Atlantic response to El Niño-Southern Oscillation induced climate variability in an ocean general circulation model. J. Geophys. Res. C Ocean 2004, 109, 1-14. [CrossRef]

14. Singleton, A.T.; Reason, C.J.C. Variability in the characteristics of cut-off low pressure systems over subtropical southern Africa. Int. J. Climatol. 2007, 27, 295-310. [CrossRef]

15. Han, W.; Meehl, G.A.; Rajagopalan, B.; Fasullo, J.T.; Hu, A.; Lin, J.; Large, W.G.; Wang, J.W.; Quan, X.W.; Trenary, L.L.; et al. Patterns of Indian Ocean sea-level change in a warming climate. Nat. Geosci. 2010, 3, 546-550. [CrossRef]

16. Han, W.; Vialard, J.; McPhaden, M.J.; Lee, T.; Masumoto, Y.; Feng, M.; De Ruijter, W.P.M. Indian ocean decadal variability: A review. Bull. Am. Meteorol. Soc. 2014, 95, 1679-1703. [CrossRef]

17. Nhantumbo, B.J.; Nilsen, J.E.Ø.; Backeberg, B.C.; Reason, C.J.C. The relationship between coastal sea level variability in South Africa and the Agulhas Current. J. Mar. Syst. 2020, 211, 1-13. [CrossRef]

18. Huang, N.E.; Shen, Z.; Long, S.R.; Wu, M.C.; Snin, H.H.; Zheng, Q.; Yen, N.C.; Tung, C.C.; Liu, H.H. The empirical mode decomposition and the Hubert spectrum for nonlinear and non-stationary time series analysis. Proc. R. Soc. Lond. Ser. A 1998, 454, 903-995. [CrossRef]

19. Huang, N.E.; Wu, Z. A Review on Hilbert-Huang Transform: Method and Its Applications. Rev. Geophys. 2008, 46, 1-23. [CrossRef]

20. Holgate, S.J.; Matthews, A.; Woodworth, P.L.; Rickards, L.J.; Tamisiea, M.E.; Bradshaw, E.; Foden, P.R.; Gordon, K.M.; Jevrejeva, S.; Pugh, J. New Data Systems and Products at the Permanent Service for Mean Sea Level. J. Coast. Res. 2013, 29, 493. [CrossRef]

21. Kalnay, E.; Kanamitsu, M.; Kistler, R.; Collins, W.; Deaven, D.; Gandin, L. The NCEP/NCAR 40-Year Reanalysis Project. Bull. Am. Meteorol. Soc. 1996, 77, 437-472. [CrossRef]

22. Huang, B.; Banzon, V.F.; Freeman, E.; Lawrimore, J.; Liu, W.; Peterson, T.C.; Smith, T.M.; Thorne, P.W.; Woodruff, S.D.; Zhang, H.M. Extended reconstructed sea surface temperature version 4 (ERSST.v4). Part I: Upgrades and intercomparisons. J. Clim. 2015, 28, 911-930. [CrossRef]

23. Saji, N.H.; Goswami, B.N.; Vinayachandran, P.N.; Yamagata, T. A dipole mode in the tropical Indian Ocean. Nature 1999, 401, 360-364. [CrossRef]

24. Ashok, K.; Guan, Z.; Yamagata, T. Impact of the Indian Ocean Dipole on the Relationship between the Indian Monsoon Rainfall and ENSO. Geophys. Res. Lett. 2001, 28, 4499-4502. [CrossRef]

25. Hendon, H.H. Indonesian Rainfall Variability: Impacts of ENSO and Local Air-Sea Interaction. J. Clim. 2003, 16, 1775-1790. [CrossRef]

26. Behera, S.K.; Luo, J.J.; Masson, S.; Delecluse, P.; Gualdi, S.; Navarra, A.; Yamagata, T. Paramount Impact of the Indian Ocean Dipole on the East African Short Rains: A CGCM Study. J. Clim. 2005, 18, 4514-4530. [CrossRef]

27. Manatsa, D.; Chingombe, W.; Matarira, C.H. The Impact of the Positive Indian Ocean Dipole on Zimbabwe Droughts. Int. J. Climatol. 2008, 28, 2011-2029. [CrossRef]

28. Manatsa, D.; Matarira, C.H.; Mukwada, G. Relative impacts of ENSO and Indian Ocean dipole/zonal mode on east SADC rainfall. Int. J. Climatol. 2011, 31, 558-577. [CrossRef]

29. Wolter, K.; Timlin, M.S. Monitoring ENSO in COADS with a seasonally adjusted principal component index. In Proceedings of the 17th Climate Diagnostics Workshop, Norman, OK, USA, 18-23 October 1992; pp. 52-57. 
30. Wolter, K.; Timlin, M.S. Measuring the strength of ENSO events: How does 1997/98 rank? Weather 1998, 53, 315-324. [CrossRef]

31. Freeman, E.; Woodruff, S.D.; Worley, S.J.; Lubker, S.J.; Kent, E.C.; Angel, W.E.; Berry, D.I.; Brohan, P.; Eastman, R.; Gates, L.; et al. ICOADS Release 3.0: A major update to the historical marine climate record. Int. J. Climatol. 2017, 37, 2211-2232. [CrossRef]

32. Lindesay, J.A. South African rainfall, the Southern Oscillation and a Southern Hemisphere semi-annual cycle. J. Climatol. 1988, 8, 17-30. [CrossRef]

33. Reason, C.J.C.; Allan, R.J.; Lindesay, J.A.; Ansell, T.J. Enso and climatic signals across the Indian Ocean basin in the global context: Part I, Interannual composite patterns. Int. J. Climatol. 2000, 20, 1285-1327. [CrossRef]

34. Marshall, G.J. Trends in the Southern Annular Mode from observations and reanalyses. J. Clim. 2003, 16, 4134-4143. [CrossRef]

35. Reason, C.J.C.; Rouault, M. Links between the Antarctic Oscillation and winter rainfall over western South Africa. Geophys. Res. Lett. 2005, 32, 1-4. [CrossRef]

36. Gillett, N.P.; Kell, T.D.; Jones, P.D. Regional climate impacts of the Southern Annular Mode. Geophys. Res. Lett. 2006, 33, 1-4. [CrossRef]

37. Huang, N.E.; Shen, Z.; Long, S.R. A NEW VIEW OF NONLINEAR WATER WAVES: The Hilbert Spectrum. Annu. Rev. Fluid Mech. 1999, 31, 417-457. [CrossRef]

38. Ezer, T.; Corlett, W.B. Is sea level rise accelerating in the Chesapeake Bay? A demonstration of a novel new approach for analyzing sea level data. Geophys. Res. Lett. 2012, 39, 1-6. [CrossRef]

39. Ezer, T.; Atkinson, L.P.; Corlett, W.B.; Blanco, J.L. Gulf Stream's induced sea level rise and variability along the U.S. mid-Atlantic coast. J. Geophys. Res. Ocean 2013, 118, 685-697. [CrossRef]

40. Wu, Z.; Huang, N.E. Ensemble empirical mode decomposition: A Noise-Assited. Adv. Adapt. Data Anal. 2009, 1, 1-41. [CrossRef]

41. Huang, N.E.; Wu, M.L.C.; Long, S.R.; Shen, S.S.P.; Qu, W.; Gloersen, P.; Fan, K.L. A confidence limit for the empirical mode decomposition and Hilbert spectral analysis. Proc. R. Soc. A Math. Phys. Eng. Sci. 2003, 459, 2317-2345. [CrossRef]

42. Soumya, M.; Vethamony, P.; Tkalich, P. Inter-annual sea level variability in the southern South China Sea. Glob. Planet. Chang. 2015, 133, 17-26. [CrossRef]

43. Saji, N.H.; Yamagata, T. Possible Impacts of Indian Ocean Dipole Mode Events on Global Climate. Clim. Res. 2003, 25, 151-169. [CrossRef]

44. Chen, X.; Feng, Y.; Huang, N.E. Global sea level trend during 1993-2012. Glob. Planet. Chang. 2014, 112, 26-32. [CrossRef]

45. Dangendorf, S.; Calafat, F.M.; Arns, A.; Wahl, T.; Haigh, I.D. Mean Sea Level Variability in the North Sea: Processes and Implications. J. Geophys. Res. Ocean 2014, 119, 6820-6841. [CrossRef]

46. Park, J.; Sweet, W. Accelerated Sea Level Rise and Florida Current Transport. Ocean Sci. 2015, 11, 607-615. [CrossRef]

47. Chafik, L.; Nilsen, J.E.Ø.; Dangendorf, S. Impact of North Atlantic teleconnection patterns on northern European sea level. J. Mar. Sci. Eng. 2017, 5, 43. [CrossRef]

48. Haigh, I.D.; Wahl, T.; Rohling, E.J.; Price, R.M.; Pattiaratchi, C.B.; Calafat, F.M.; Dangendorf, S. Timescales for detecting a significant acceleration in sea level rise. Nat. Commun. 2014, 5, 1-11. [CrossRef]

49. Zebiak, S.E. Air-sea interaction in the equatorial Atlantic region. J. Clim. 1993, 6, 1567-1586. [CrossRef]

50. Neelin, J.D.; Battisti, D.S.; Hirst, A.C.; Jin, F.-F.; Wakata, Y.; Yamagata, T.; Zebiak, S.E. ENSO theory. J. Geophys. Res. 1998, 103, 14261-14290. [CrossRef]

51. Taljaard, J.J. Synoptic Meteorology of the Southern Hemisphere. In Meteorology of the Southern Hemisphere: Meteorological Monographs; Newton, C.W., Ed.; American Meteorological Society: Boston, MA, USA, 1972; Volume 13, pp. 139-213. [CrossRef]

52. Van Loon, H. Wind in the Southern Hemisphere. In Meteorology of the Southern Hemisphere: Meteorological Monographs; Newton, C.W., Ed.; American Meteorological Society: Boston, MA, USA, 1972; Volume 13, pp. 87-100. [CrossRef]

53. Preston-Whyte, R.A.; Tyson, P.D. The Atmosphere and Weather of Southern Africa, 1st ed.; Oxford University Press: Cape Town, South Africa, 1988.

54. Tyson, P.D.; Preston-Whyte, R.A. The Weather and Climate of Southern Africa, 2nd ed.; Oxford University Press: Cape Town, South Africa, 2000.

55. Pugh, D.T. Tides, Surges and Mean Sea-Level; John Wiley \& Sons: Chichester, UK, 1987.

56. Chelton, D.B.; Davis, R.E. Monthly Mean Sea-Level Variability Along the West Coast of North America. J. Phys. Oceanogr. 1982, 12, 757-784. [CrossRef]

57. Richter, K.; Segtnan, O.H.; Furevik, T. Variability of the Atlantic Inflow to the Nordic Seas and Its Causes Inferred from Observations of Sea Surface Height. J. Geophys. Res. 2012, 117, 1-12. [CrossRef]

58. Calafat, F.M.; Chambers, D.P.; Tsimplis, M.N. Inter-annual to decadal sea-level variability in the coastal zones of the Norwegian and Siberian Seas: The role of atmospheric forcing. J. Geophys. Res. Ocean 2013, 118, 1287-1301. [CrossRef]

59. Woodworth, P.L.; Teferle, F.N.; Bingley, R.M.; Shennan, I.; Williams, S.D.P. Trends in UK mean sea level revisited. Geophys. J. Int. 2009, 176, 19-30. [CrossRef]

60. Ezer, T.; Haigh, I.D.; Woodworth, P.L. Nonlinear Sea-Level Trends and Long-Term Variability on Western European Coasts. J. Coast. Res. 2016, 320, 744-755. [CrossRef] 